\title{
Size-Dependent Self-Limiting Oxidation of Free Palladium Clusters
}

\author{
Sandra M. Lang, ${ }^{\dagger}$ Irene Fleischer, ${ }^{\dagger}$ Thorsten M. Bernhardt, ${ }^{, \dagger}$ Robert N. Barnett, ${ }^{\ddagger}$ and Uzi Landman*, \\ ${ }^{\dagger}$ Institute of Surface Chemistry and Catalysis, University of Ulm, Albert-Einstein-Allee 47, 89069 Ulm, Germany \\ ${ }^{\ddagger}$ School of Physics, Georgia Institute of Technology, Atlanta, Georgia 30332-0430, United States
}

ABSTRACT: Temperature-dependent gas phase ion trap experiments performed under multicollision conditions reveal a strongly size-dependent reactivity of $\mathrm{Pd}_{x}^{+}(x=2-7)$ in the reaction with molecular oxygen. Yet, a particular stability and resistance to further oxidation is generally observed for reaction products with two oxygen molecules, $\mathrm{Pd}_{x} \mathrm{O}_{4}{ }^{+}$. Complementary first-principles density functional theory simulations elucidate the details of the size-dependent bonding of oxygen to the small palladium clusters and are able to assign the pronounced occurrence of $\mathrm{Pd}_{x} \mathrm{O}_{4}{ }^{+}$complexes to a dissociatively chemisorbed bridging oxygen atomic structure which impedes the chemisorption of further oxygen molecules. The molecular physisorption of additional $\mathrm{O}_{2}$ is only observed at cryogenic temperatures. Additional

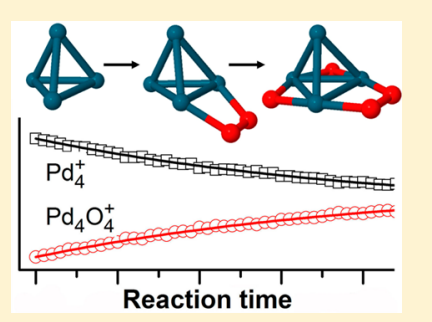
experiments and simulations employing preoxidized clusters $\mathrm{Pd}_{x} \mathrm{O}^{+}(x=2-8)$ and $\mathrm{Pd}_{x} \mathrm{O}_{2}^{+}(x=4-7)$ confirm the formation of the two different oxygen species.

\section{INTRODUCTION}

Palladium is one of the most often employed metals in catalysis, ${ }^{1}$ particularly because of its use in three-way catalysts in automotive exhaust systems, ${ }^{2}$ and its potential in the catalytic low temperature methane combustion. ${ }^{3}$ The activity, selectivity, and specificity of oxidation catalysts are often governed, in addition to the particle size, morphology, and structure, by the chemical nature of the catalyst's surface, which may differ in the presence of oxygen from its native (bare) state; for studies on single crystal surfaces of transition metals see, e.g., citations 320 in ref 4 . The importance of intermediate surface oxide phases has been recognized rather recently. ${ }^{5}$ Subsequent investigations revealed different oxygen species on palladium surfaces, ${ }^{6}$ and that the type of palladium surface oxide may control the catalyzed reaction pathway. ${ }^{7}$

Oxidation processes of palladium particles supported on metal-oxide surfaces have been extensively studied for model catalyst systems with size distributions of the investigated supported particles being mostly in the several nanometer range, ${ }^{4,8,9}$ but smaller ones have also been studied. ${ }^{10-14}$ One of the most interesting findings of these studies pertains to partial oxidation of the supported palladium particles, which was found to be limited to the interfacial region between the particle and the underlying supporting surface (most often a metal-oxide, e.g., magnesia, titania, alumina).

In the past decade a most challenging research direction has been the study of reactions catalyzed by nanoclusters (in particular, experiments and theories on size-selected clusters), in the regime where scaling of the probed properties with cluster size does not apply. ${ }^{15}$ This nonscaling regime pertains to clusters with sizes ranging between just several atoms and up to a few dozen atoms, where the cluster properties (structural, electronic, dynamical, and chemical) vary in a nonmonotonic manner with the number of atoms. These findings, and in particular the observations of a strongly particle-size-dependent formation of different oxygen species, ${ }^{13,14,16-20}$ pose significant fundamental challenges. ${ }^{7}$

In an attempt to describe more closely the actual catalytic environment, the majority of scientific investigations addressing the above issues focused on surface-supported metal (e.g., palladium) particles. However, certain factors-particularly those associated with modifications of structural and electronic cluster properties induced by the interaction with the supporting substrate-though of intrinsic interest in their own right-complicate the analysis pertaining to the fundamental steps of oxygen interaction with the nanoscale metal clusters. Further insights into these complex issues may be gained through experimental and theoretical explorations on free palladium clusters.

Effective oxidation of gas phase palladium clusters without significant size dependence has experimentally been found previously for anionic ${ }^{21,22}$ and neutral ${ }^{23}$ clusters. Ultraviolet photoelectron spectroscopy on $\mathrm{Pd}_{x} \mathrm{O}_{2}^{-}$demonstrated the dissociative binding of a first oxygen molecule to the anionic palladium atom yielding a linear $\mathrm{O}-\mathrm{Pd}-\mathrm{O}$ geometry in agreement with previous studies; ${ }^{24}$ however, the structure of the complexes $\mathrm{Pd}_{x} \mathrm{O}_{2}^{-}(x=2-7)$ could not be clearly assigned. $^{21}$ The oxygen chemisorption pattern was suggested to be dominated by the electronic properties of the clusters rather than by specific adsorption sites. Detailed spin density functional theory studies revealed dissociative adsorption of a first oxygen molecule on $\operatorname{Pd}_{x}(x=2-4)$ with the oxygen atoms sitting on $\mathrm{Pd}$ bridge sites whereas the palladium atom prefers molecular $\mathrm{O}_{2}$ adsorption. Furthermore, all ground state isomers were found to remain in the same spin state as found for the

Special Issue: A. W. Castleman, Jr. Festschrift

Received: March 19, 2014

Revised: $\quad$ May 25, 2014

Published: June 10, 2014 
bare palladium clusters with the exception of $\mathrm{Pd}_{4} \mathrm{O}_{2} \cdot{ }^{25}$ In agreement with this observation, $\mathrm{Pd}_{4} \mathrm{O}_{2}^{-/ 0 /+}$ complexes containing dissociated oxygen have been theoretically found to be energetically more favorable than complexes containing molecular oxygen. ${ }^{26}$

Recently, we reported for the first time on the oxidation of free cationic palladium clusters $\mathrm{Pd}_{x}^{+}(x=2-5)^{27}$ as well as $\mathrm{Pd}_{6}^{+}$ and $\mathrm{Pd}_{7}{ }^{+28}$ performed in an ion trap under multicollision conditions. In the present contribution we have extended these investigations and compare the room temperature kinetics and the temperature-dependent oxidation in the whole size range between two and seven atoms. The investigation has further been expanded to include the reactivity of initially partially preoxidized palladium clusters $\mathrm{Pd}_{x} \mathrm{O}^{+}(x=2-8)$ and $\mathrm{Pd}_{x} \mathrm{O}_{2}{ }^{+}(x$ = 4-7) toward molecular oxygen. Furthermore, we present a full account of complementary first-principles density functional theory (DFT) calculations. In particular, we address the bonding and activation of oxygen on palladium nanocluster cations, the size and temperature dependence of the cluster oxidation process, its self-limiting nature, and the types of adsorbed oxygen species, that is, activated $\mathrm{O}_{2}$ adsorption, dissociative chemisorption, and weak nonactivated molecular physisorption.

\section{METHODS}

A. Experimental Setup and Data Evaluation. The experiments were performed in a radiofrequency (rf)-octopole ion trap which is operated under multicollision conditions and embedded into a low-energy ion beam quadrupole mass spectrometer system as described in detail elsewhere. ${ }^{29}$

Palladium cluster cations and their oxides were generated by simultaneous sputtering of four metal targets with high energetic Xe ions produced in a CORDIS (cold reflex discharge ion source). ${ }^{30}$ The hot clusters were first thermalized and collimated in a helium filled quadrupole ion guide before massselection of a desired cluster size. Due to the broad natural isotope distribution of palladium only reactions of clusters with up to eight $\mathrm{Pd}$ atoms were investigated here to render the product assignment unambiguous. ${ }^{31,32}$

The cluster ion beam containing only one specific cluster size was then transferred into a home-built temperature variable octopole ion trap. In this trap, ions are radially confined by a two-dimensional rf-field whereas axial confinement is achieved by two switchable electrodes placed in front and behind the rfoctopole. The ion trap was prefilled with about $1 \mathrm{~Pa}$ helium buffer gas and a small well-defined fraction of molecular oxygen (typically $0.005-0.12 \mathrm{~Pa}$ ). At this pressure multicollision conditions are ensured in the ion trap. Temperature adjustment in the range between 20 and $300 \mathrm{~K}$ is achieved by a combination of a helium cryostat and a resistive heater. Under the applied pressure conditions, thermal equilibration of the clusters via collisions with the helium buffer gas is achieved within a few milliseconds whereas typical storage times range from $0.1 \mathrm{~s}$ up to several seconds. ${ }^{29}$

After a chosen reaction time, all charged cluster complexes, intermediates and final products, were extracted from the ion trap by applying a pulsed bias potential to the exit electrode of the ion trap and the ion distribution was mass analyzed in a second quadrupole mass spectrometer. To derive quantitative data, kinetic measurements were performed by recording the intensity of all charged species as a function of reaction time, i.e., the storage time in the ion trap.
The normalized kinetic traces were evaluated by fitting integrated rate equations of proposed potential reaction mechanisms to the experimental data using the software package "Detmech". ${ }^{33}$ This leads to the determination of the simplest reaction mechanism that best fits the data as well as to the corresponding rate constants $k$.

The total pressure in the ion trap amounted to about $1 \mathrm{~Pa}$, which means that the experiment, although performed under multicollision conditions, is operated in the kinetic low pressure regime. Thus, each association reaction step, e.g.,

$$
\mathrm{Pd}_{x}^{+}+\mathrm{O}_{2} \rightarrow \mathrm{Pd}_{x} \mathrm{O}_{2}^{+} \quad k
$$

can be described by the Lindemann energy transfer model for association reactions, ${ }^{34}$ which includes the following elementary reaction steps

$$
\begin{aligned}
& \mathrm{Pd}_{x}^{+}+\mathrm{O}_{2} \rightleftarrows\left(\mathrm{Pd}_{x} \mathrm{O}_{2}^{+}\right)^{*} \quad k_{\mathrm{a}}, k_{\mathrm{d}} \\
& \left(\mathrm{Pd}_{x} \mathrm{O}_{2}^{+}\right)^{*}+\mathrm{He} \rightarrow \mathrm{Pd}_{x} \mathrm{O}_{2}^{+}+\mathrm{He}^{*} \quad k_{\mathrm{s}}
\end{aligned}
$$

$k_{a}, k_{\mathrm{d}}$, and $k_{\mathrm{s}}$ denote the rate constants for the association reaction $\left(k_{\mathrm{a}}\right)$ of $\mathrm{Pd}_{x}^{+}$with $\mathrm{O}_{2}$ yielding the energized complex $\left(\mathrm{Pd}_{x} \mathrm{O}_{2}^{+}\right)^{*}$, the decomposition rate constant $\left(k_{\mathrm{d}}\right)$ for unimolecular decomposition of this complex, and the stabilization rate constant $\left(k_{\mathrm{s}}\right)$ resulting in the stabilization of the energized complex via helium collision. Thus, the overall reaction 1 depends on the oxygen $\left[\mathrm{O}_{2}\right]$ as well as helium buffer gas concentration $[\mathrm{He}]$ and the corresponding measured pseudo-first-order rate constant $k$ is given by ${ }^{34}$

$$
k=k^{(3)}[\mathrm{He}]\left[\mathrm{O}_{2}\right]
$$

Because the rate constants $k_{\mathrm{a}}$ and $k_{\mathrm{s}}$ are well represented by ion-molecule collision rate coefficients and are thus temperature independent, any observed temperature dependence must be contained in the unimolecular decomposition rate constant $k_{\mathrm{d}}{ }^{35}$ The activation barrier of this unimolecular decomposition results in a negative temperature dependence for the overall reaction 1 and thus in an enhanced reactivity with decreasing temperature. ${ }^{36}$ Furthermore, this also means that oxidation products $\mathrm{Pd}_{x} \mathrm{O}_{y}{ }^{+}$observed at room temperature must contain strongly bound oxygen whereas products with low $\mathrm{Pd}_{x}^{+}-\mathrm{O}_{y}$ binding energies are only observed at lower temperatures.

B. Theoretical Methods. The theoretical explorations of the atomic arrangements and electronic structures of $\mathrm{Pd}_{x}^{+}$ clusters and their complexes with oxygen were performed with the use of first-principles density functional theory (DFT) calculations. In particular, we employed the Born-Oppenheimer (BO)-spin density functional (SDF)-molecular dynamics (MD) method, BO-SDF-MD ${ }^{37}$ with norm-conserving soft (scalar relativistic for Pd) pseudopotentials ${ }^{38}$ and the generalized gradient approximation (GGA) ${ }^{39}$ for electronic exchange and correlations. In these calculations we have used a plane-wave basis with a kinetic energy cutoff $E_{\mathrm{c}}=110 \mathrm{Ry}$, which yields convergence. This corresponds to a real-space grid spacing of $0.3 \mathrm{a}_{0}$; the real-space grid spacing for the density was $0.1 \mathrm{a}_{0}$ corresponding to $E_{\mathrm{c}}=987 \mathrm{Ry}$. In the construction of the Pd pseudopotentials the valence electrons, $4 \mathrm{~s}^{2}, 4 \mathrm{p}^{6}$, and $4 \mathrm{~d}^{10}$, were characterized by core radii $r_{\mathrm{c}}=0.85 \mathrm{a}_{0}, 0.90 \mathrm{a}_{0}$, and $1.15 \mathrm{a}_{0}$, respectively, with the $s$ orbital treated as local; $a_{0}$ is the Bohr radius. The BO-SDF-MD method is particularly suitable for investigations of charged systems because it does not employ a supercell (i.e., no periodic replication of the ionic system is 
used). Structural optimizations were performed using a conjugate-gradient-like method.

For reference we compare the values obtained by us for a couple of simple Pd-containing compounds with measured results. For the dimer $\mathrm{Pd}_{2}$ we obtain a binding energy $E(\mathrm{Pd}-$ $\mathrm{Pd})=1.34 \mathrm{eV}$, and a bond-length $d=2.47 \AA$, compared to measured values ${ }^{40}$ of $1.04 \mathrm{eV}$ and $2.8 \AA$ A. For PdO we obtained $E(\mathrm{Pd}-\mathrm{O})=3.19 \mathrm{eV}$ and $d=1.79 \AA$, compared to a measured value of $2.9 \mathrm{eV}^{41}$

\section{RESULTS AND DISCUSSION}

A. Cluster-Size-Dependent Room Temperature Oxidation of $\mathrm{Pd}_{\boldsymbol{x}}^{+}$. Figure 1 (left column) displays ion mass distributions (representing steady-state equilibrium distributions, except for $\mathrm{Pd}_{2}^{+}$) obtained after the reaction of bare
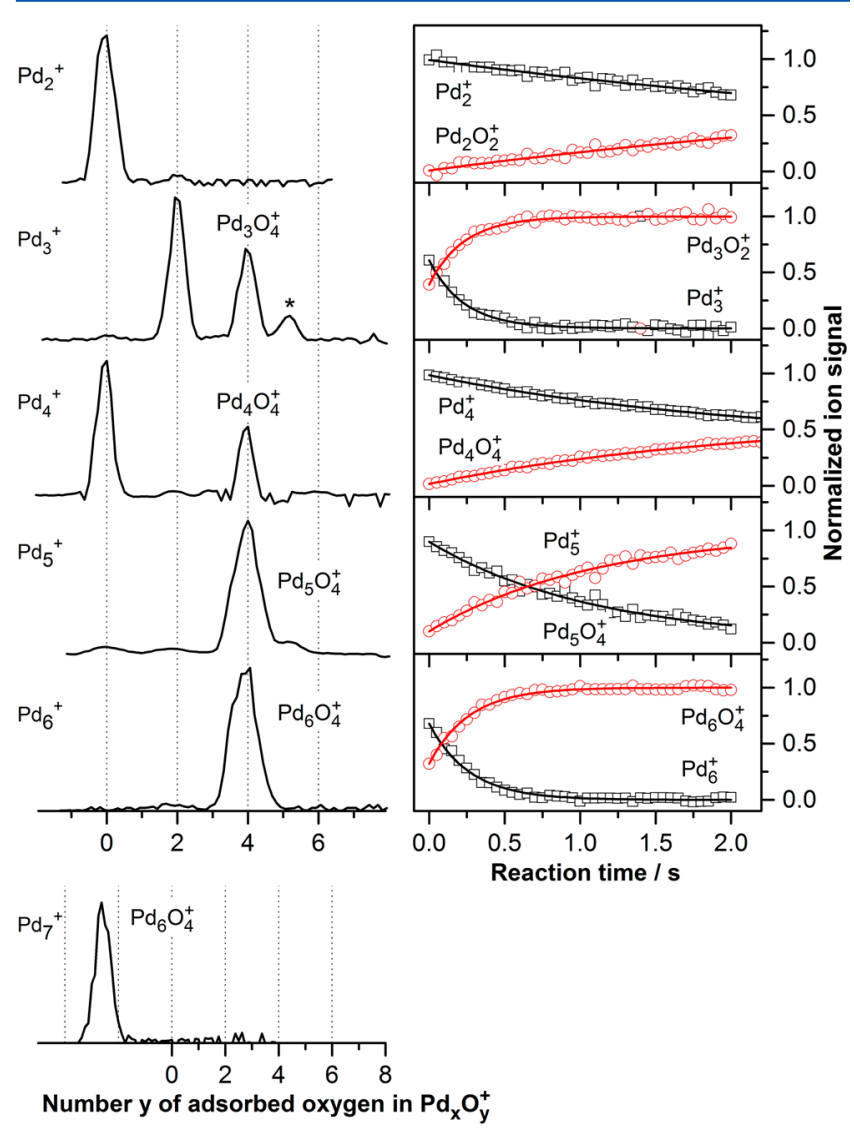

Figure 1. Reaction of palladium cations $\operatorname{Pd}_{x}^{+}(x=2-7)$ with molecular oxygen at room temperature. Left column: cluster-sizedependent steady-state equilibrium (except for $\mathrm{Pd}_{2}^{+}$) product mass spectra obtained after a reaction time of $0.1 \mathrm{~s}\left(p(\mathrm{He})=1 \mathrm{~Pa} ; \mathrm{Pd}_{2}{ }^{+}\right.$, $\left.p\left(\mathrm{O}_{2}\right)=0.12 \mathrm{~Pa} ; \mathrm{Pd}_{3,4,6}{ }^{+}, p\left(\mathrm{O}_{2}\right)=0.10 \mathrm{~Pa} ; \mathrm{Pd}_{5,7}{ }^{+}, p\left(\mathrm{O}_{2}\right)=0.07 \mathrm{~Pa}\right)$. Right column: reaction kinetic data obtained under kinetically controlled low $\mathrm{O}_{2}$ pressure conditions $\left(p(\mathrm{He})=1 \mathrm{~Pa} ; \mathrm{Pd}_{3,5}{ }^{+}, p\left(\mathrm{O}_{2}\right)\right.$ $\left.=0.008 \mathrm{~Pa} ; \mathrm{Pd}_{4,6}^{+}, p\left(\mathrm{O}_{2}\right)=0.010 \mathrm{~Pa} ; \mathrm{Pd}_{2}^{+}: p\left(\mathrm{O}_{2}\right)=0.073 \mathrm{~Pa}\right)$. The open symbols represent experimental data, whereas the solid lines are obtained by fitting the integrated rate equations of the proposed reaction mechanisms to the experimental data (see text for details). The product labeled with an asterisk is due to water impurities present in this particular experiment. Please note that due to the low reactivity of $\mathrm{Pd}_{2}{ }^{+}$the reaction always proceeds under kinetic control and does not reach steady-state equilibrium conditions on the time scale of the experiment. Furthermore, elevated pressure conditions are necessary for kinetic measurements compared to all other cluster sizes. Finally, $\mathrm{Pd}_{7}{ }^{+}$reacts too fast for kinetic data to be obtainable in our experiment. palladium cations $\mathrm{Pd}_{x}^{+}$with $0.07-0.12 \mathrm{~Pa}$ of molecular oxygen (depending on the cluster size) at room temperature. ${ }^{27,28}$ These mass spectra already indicate distinct cluster size specific differences in the reactivity. For $\mathrm{Pd}_{2}{ }^{+}$only a marginal signal corresponding to $\mathrm{Pd}_{2} \mathrm{O}_{2}{ }^{+}$is observed after a reaction time of 0.1 s. In contrast, $\mathrm{Pd}_{3}{ }^{+}$reacts fast with up to two $\mathrm{O}_{2}$ molecules, yielding $\mathrm{Pd}_{3} \mathrm{O}_{2}{ }^{+}$and $\mathrm{Pd}_{3} \mathrm{O}_{4}{ }^{+}$. The larger clusters $\mathrm{Pd}_{4}{ }^{+}-\mathrm{Pd}_{6}{ }^{+}$ exhibit only a single adsorption product, which contains two oxygen molecules, $\mathrm{Pd}_{x} \mathrm{O}_{4}^{+}(x=4-6) . \mathrm{Pd}_{7}^{+}$is the only investigated cluster size that does not form stable products with molecular oxygen but completely fragments into $\mathrm{Pd}_{6} \mathrm{O}_{4}{ }^{+}$upon reaction with $\mathrm{O}_{2}$.

To quantify the observed cluster-size-dependent oxygenation of palladium cations, kinetic measurements were performed under low $\mathrm{O}_{2}$ pressure (kinetically controlled) conditions as shown in Figure 1 (right column, open symbols). For $\mathrm{Pd}_{3}{ }^{+}$, $\mathrm{Pd}_{5}^{+}$, and $\mathrm{Pd}_{6}^{+}$the straightforward association reaction, eq 1 , represents the mechanism that best fits these kinetic data. This indicates the formation of stable products $\mathrm{Pd}_{x} \mathrm{O}_{y}{ }^{+}$, which exhibit negligible back-reaction and potentially contain dissociated $\mathrm{O}_{2}$.

In contrast, the reaction of $\mathrm{Pd}_{2}^{+}$and $\mathrm{Pd}_{4}^{+}$can be best described by an equilibrium reaction mechanism

$$
\mathrm{Pd}_{x}^{+}+\mathrm{O}_{2} \rightleftarrows \mathrm{Pd}_{x} \mathrm{O}_{2}^{+} \quad k_{1}, k_{-1}
$$

with $k_{1}$ and $k_{-1}$ denoting the rate constants for the forward and backward reaction steps, respectively. The observation of backreaction steps suggests (weak) molecular adsorption of the first $\mathrm{O}_{2}$ molecule and/or activation barriers for the formation of more stable $\mathrm{Pd}_{x} \mathrm{O}_{y}^{+}$complexes with dissociated oxygen.

The solid lines in Figure 1 (right column) represent the integrated rate equations of these mechanisms fitted to the experimental data and the thus obtained corresponding termolecular rate constants for the forward reaction step, $k_{1}{ }^{(3)}$, are shown in Figure 2 as a function of the cluster size.

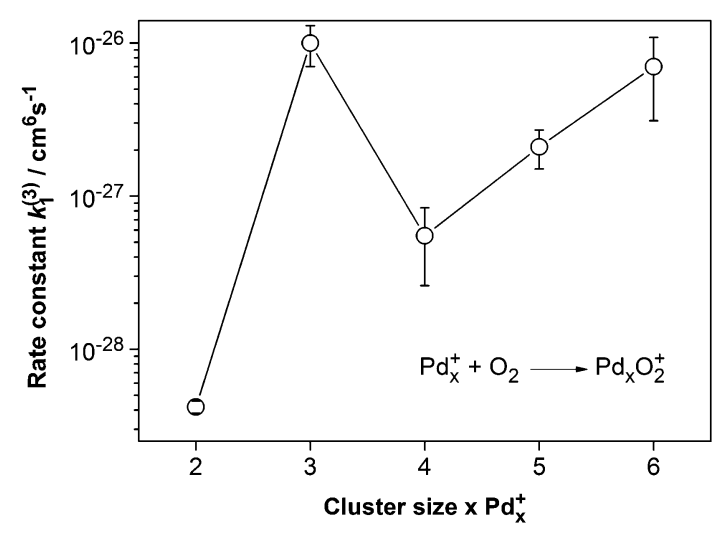

Figure 2. Cluster-size-dependent termolecular rate constants $k_{1}^{(3)}$ for the adsorption of a first $\mathrm{O}_{2}$ molecule on $\mathrm{Pd}_{x}{ }^{+}$obtained from the reaction kinetic data shown in Figure 1 (right column).

Please note that for $\mathrm{Pd}_{4}^{+}, \mathrm{Pd}_{5}^{+}$, and $\mathrm{Pd}_{6}^{+}$only the product $\mathrm{Pd}_{x} \mathrm{O}_{4}{ }^{+}$is observed and the intermediate $\mathrm{Pd}_{x} \mathrm{O}_{2}{ }^{+}$is not detected. This observation indicates that the adsorption of a first oxygen molecule represents the rate-determining reaction step whereas the adsorption of the second $\mathrm{O}_{2}$ proceeds faster than the time resolution of our experiment. Hence, the measured rate constants correspond to the formation of $\mathrm{Pd}_{x} \mathrm{O}_{2}^{+}$ and can be directly compared with the rate constants obtained for $\mathrm{Pd}_{2}{ }^{+}$and $\mathrm{Pd}_{3}{ }^{+}$. Figure 2 clearly shows that the reactivity toward a first adsorbed oxygen molecule follows the order $\mathrm{Pd}_{2}{ }^{+}$ 
$<\mathrm{Pd}_{4}{ }^{+}<\mathrm{Pd}_{5}{ }^{+}<\mathrm{Pd}_{6}{ }^{+}<\mathrm{Pd}_{3}{ }^{+}$with termolecular rate constants $k_{1}{ }^{(3)}$ amounting to $0.042 \pm 0.004 \times 10^{-27} \mathrm{~cm}^{6} \mathrm{~s}^{-1}\left(\mathrm{Pd}_{2}^{+}\right), 0.55$ $\pm 0.29 \times 10^{-27} \mathrm{~cm}^{6} \mathrm{~s}^{-1}\left(\mathrm{Pd}_{4}^{+}\right), 2.1 \pm 0.6 \times 10^{-27} \mathrm{~cm}^{6} \mathrm{~s}^{-1}$ $\left(\mathrm{Pd}_{5}^{+}\right), 7.0 \pm 3.9 \times 10^{-27} \mathrm{~cm}^{6} \mathrm{~s}^{-1}\left(\mathrm{Pd}_{6}^{+}\right)$, and $10 \pm 3 \times 10^{-27}$ $\mathrm{cm}^{6} \mathrm{~s}^{-1}\left(\mathrm{Pd}_{3}^{+}\right){ }^{27,28}$

B. Temperature-Dependent Formation of Different Oxygen Species. To gain more insight into the above indicated cluster size specific oxidation processes on small palladium clusters, temperature-dependent reaction experiments have been carried out for $\operatorname{Pd}_{x}^{+}(x=2-7)$. Additionally, the reactivities of partially preoxidized $\mathrm{Pd}_{x} \mathrm{O}^{+}(x=2-8)$ and $\mathrm{Pd}_{x} \mathrm{O}_{2}^{+}(x=4-7)$ have been studied. Furthermore, detailed quantum mechanical first-principles simulations have been performed on these systems to elucidate the bonding and activation of molecular oxygen on palladium clusters.

The maximum number of adsorbed oxygen atoms on $\mathrm{Pd}_{x}^{+}$as well as on the singly oxidized $\mathrm{Pd}_{x} \mathrm{O}^{+}$as a function of the reaction temperature obtained under equilibrium reaction conditions is displayed in Figure 3. This plot illustrates that

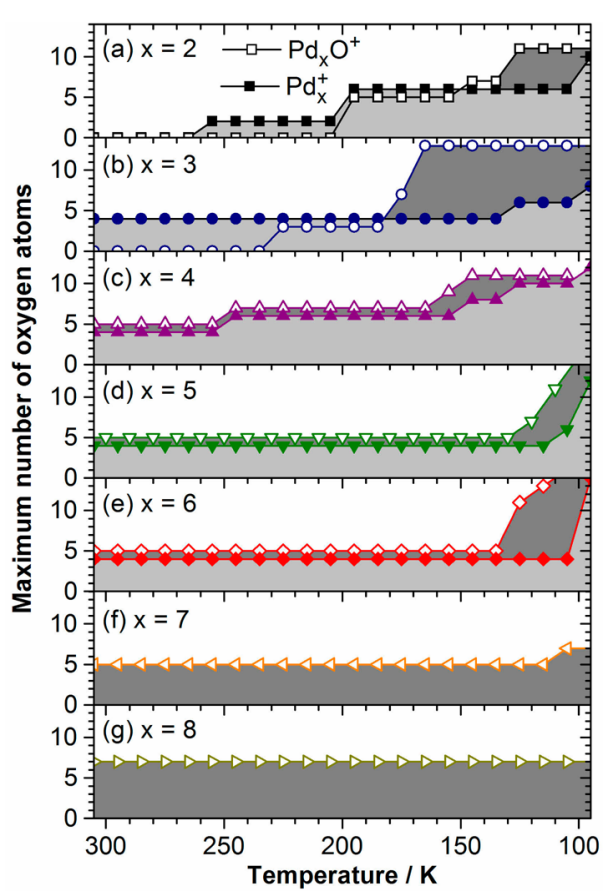

Figure 3. Maximum number $y$ of adsorbed oxygen on $\mathrm{Pd}_{x}^{+}$(filled symbols) and $\mathrm{Pd}_{x} \mathrm{O}^{+}$(open symbols) as a function of the reaction temperature. The data are obtained from steady-state equilibrium ion mass distributions (except for $\mathrm{Pd}_{2}^{+}$) obtained after a reaction time of $0.1 \mathrm{~s}\left(p(\mathrm{He})=1 \mathrm{~Pa} ; \mathrm{Pd}_{2}^{+}, p\left(\mathrm{O}_{2}\right)=0.12 \mathrm{~Pa} ; \mathrm{Pd}_{3,4,6}{ }^{+}, p\left(\mathrm{O}_{2}\right)=0.10 \mathrm{~Pa}\right.$; $\left.\mathrm{Pd}_{5,7}{ }^{+}, p\left(\mathrm{O}_{2}\right)=0.07 \mathrm{~Pa}\right)$. Please note that $\mathrm{Pd}_{7}^{+}$completely fragments to yield $\mathrm{Pd}_{6} \mathrm{O}_{4}^{+} \cdot \mathrm{Pd}_{6} \mathrm{O}_{4}^{+}$is also a major fragment of the reaction of $\mathrm{Pd}_{7} \mathrm{O}^{+}$with oxygen and only the nonfragmented product $\mathrm{Pd}_{7} \mathrm{O}_{5}{ }^{+}$is included in graph (f). In the case of $\mathrm{Pd}_{8}{ }^{+}$data could only be obtained for $\mathrm{Pd}_{8} \mathrm{O}^{+}(\mathrm{g})$.

the small clusters $\mathrm{Pd}_{2}^{+}, \mathrm{Pd}_{2} \mathrm{O}^{+}$, and $\mathrm{Pd}_{3} \mathrm{O}^{+}$do not react with oxygen at room temperature but sequentially adsorb multiple $\mathrm{O}_{2}$ with decreasing reaction temperature at the applied conditions. In contrast, all other cluster sizes $\mathrm{Pd}_{x}^{+}(x=3-6)$ and $\mathrm{Pd}_{x} \mathrm{O}^{+}(x=4-7)$ preferably react with two oxygen molecules, yielding $\mathrm{Pd}_{x} \mathrm{O}_{4}^{+}$and $\mathrm{Pd}_{x} \mathrm{O}_{5}{ }^{+}$, respectively, at room temperature whereas $\mathrm{Pd}_{8} \mathrm{O}^{+}$reacts with three $\mathrm{O}_{2}$ forming $\mathrm{Pd}_{8} \mathrm{O}_{7}{ }^{+}$. These complexes appear to be particularly stable and inert toward further reaction with oxygen over a wide temperature range. Adsorption of additional oxygen molecules is only observed at considerably lower temperatures.

These experimental findings indicate the formation of two different types of adsorbed oxygen: (1) Room temperature chemisorption of up to two oxygen molecules on $\mathrm{Pd}_{x}^{+}(x=3-$ 6) and $\mathrm{Pd}_{x} \mathrm{O}^{+}(x=4-7)$ (up to three $\mathrm{O}_{2}$ on $\mathrm{Pd}_{8} \mathrm{O}^{+}$) that apparently self-limits (hinders) further oxygen adsorption in a wide temperature range. (2) Sequential low temperature physisorption of multiple oxygen molecules on $\mathrm{Pd}_{x}^{+}(x=2-$ 6) and $\mathrm{Pd}_{x} \mathrm{O}^{+}(x=2-7)$. The formation of these different types of oxygen as well as its cluster size and temperature dependence will be discussed in the following for each investigated cluster size in conjunction with the results of our DFT calculations.

1. $\mathrm{Pd}_{2} \mathrm{O}_{y}{ }^{+} \cdot \mathrm{Pd}_{2}{ }^{+}$and $\mathrm{Pd}_{2} \mathrm{O}^{+}$hardly adsorb molecular oxygen at room temperature and a measurable formation of oxygen products is only observed at elevated $\mathrm{O}_{2}$ pressure as well as at reaction times longer than $1 \mathrm{~s}$ (Figure 1). At typical pressure conditions applied in the ion trap experiments, sequential oxygen adsorption only occurs below $200 \mathrm{~K}$, indicating weak oxygen physisorption (cf. Figure 3 ).

According to our theoretical simulations the first two oxygen molecules are molecularly bound to $\mathrm{Pd}_{2}{ }^{+}$in the ground state configuration each bridging the two palladium atoms as displayed in Figure 4a. The adsorption energy of the first $\mathrm{O}_{2}$
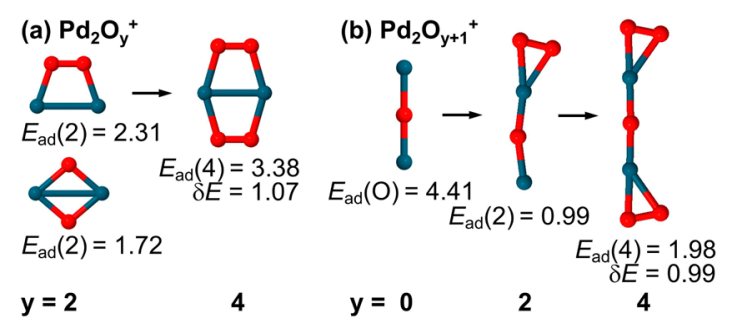

Figure 4. (a) Ground state atomic structures of (a) $\mathrm{Pd}_{2} \mathrm{O}_{y}^{+}, y=2,4$, and (b) $\mathrm{Pd}_{2} \mathrm{O}_{y+1}{ }^{+}, y=0$, 2, 4. For $\mathrm{Pd}_{2} \mathrm{O}_{2}^{+}$we show in addition an optimized isomeric structure with dissociated $\mathrm{O}_{2}$. The $\mathrm{Pd}$ and $\mathrm{O}$ atoms are represented by blue and red spheres, respectively. Next to each structure we give the total adsorption energy, $E_{\mathrm{ad}}(y)$, relative to the bare cluster and free $(y / 2) \mathrm{O}_{2}$ molecules, $E_{\text {ad }}(y)=E\left[\mathrm{Pd}_{x}^{+}\right]+(y / 2)$ $E\left[\mathrm{O}_{2}\right]-E\left[\mathrm{Pd}_{x} \mathrm{O}_{y}{ }^{+}\right]$for $\mathrm{Pd}_{x} \mathrm{O}_{y}{ }^{+}$and $E_{\mathrm{ad}}(y)=E\left[\mathrm{Pd}_{x} \mathrm{O}^{+}\right]+(y / 2) E\left[\mathrm{O}_{2}\right]-$ $E\left[\mathrm{Pd}_{x} \mathrm{O}_{y+1}{ }^{+}\right]$for $\mathrm{Pd}_{x} \mathrm{O}_{y+1}{ }^{+}$, respectively. Below it we give the adsorption energy of the last-added oxygen molecule $\delta E=E_{\mathrm{ad}}(y)-E_{\mathrm{ad}}(y-2)$. $E_{\text {ad }}(\mathrm{O})$ denotes the binding energy of the single oxygen atom in $\mathrm{Pd}_{x} \mathrm{O}^{+}$. Energies are given in units of electronvolts.

is rather high $\left(E_{\mathrm{ad}}(2)=2.31 \mathrm{eV}\right)$ whereas the second $\mathrm{O}_{2}$ is bound less strongly $(\delta E=1.07 \mathrm{eV})$, resulting in a total adsorption energy of both $\mathrm{O}_{2}$ molecules of $E_{\mathrm{ad}}(4)=3.38 \mathrm{eV}$. Figure $4 \mathrm{a}$ also shows an isomeric structure of $\mathrm{Pd}_{2} \mathrm{O}_{2}{ }^{+}$ comprising dissociated atomically adsorbed oxygen which, however, results in a smaller total adsorption energy $\left(E_{\text {ad }}(2)=\right.$ $1.72 \mathrm{eV}$ ) of the two oxygen atoms.

The ground state structure of $\mathrm{Pd}_{2} \mathrm{O}^{+}$is represented by a $\mathrm{Pd}-$ $\mathrm{O}-\mathrm{Pd}$ linear chain with the oxygen atom bound by $E_{\mathrm{ad}}(\mathrm{O})=$ $4.41 \mathrm{eV}$ (cf. Figure 4b). In contrast to $\mathrm{Pd}_{2}{ }^{+}$, the first two $\mathrm{O}_{2}$ molecules are bound molecularly in an "end-bonded" configuration to $\mathrm{Pd}_{2} \mathrm{O}^{+}$with equal binding energies of 0.99 $\mathrm{eV}$ each.

The experimentally observed weak reactivity of $\mathrm{Pd}_{2}^{+}$seems to be apparently in contrast to the theoretically predicted high binding energy of the first $\mathrm{O}_{2}$ molecule to $\mathrm{Pd}_{2}{ }^{+}$(cf. Figure 4). Yet, the seemingly low reactivity of $\mathrm{Pd}_{2}^{+}$in the experiment (manifested by the small room temperature termolecular rate 
constant of $0.042 \pm 0.004 \times 10^{-27} \mathrm{~cm}^{6} \mathrm{~s}^{-1}$ ) can be attributed to the limited size of the cluster. According to the Lindemann energy transfer model for association reactions (cf. section IIA) an energized complex $\left(\mathrm{Pd}_{2} \mathrm{O}_{2}^{+}\right) *$ is formed upon reaction of $\mathrm{Pd}_{2}{ }^{+}$with $\mathrm{O}_{2}$. This complex has only a comparably small number of degrees of freedom available for energy redistribution. If, therefore, a large binding energy is liberated in the process of the formation of the energized complex $\left(\mathrm{Pd}_{2} \mathrm{O}_{2}^{+}\right)^{*}$, this excess energy cannot be efficiently redistributed before the stabilizing collision with a He atom (eq $2 b$ ), the complex has a very short lifetime, and the unimolecular decomposition (backreaction, $k_{\mathrm{d}}$ in eq $2 \mathrm{a}$ ) prevails under the experimental low pressure conditions.

2. $\mathrm{Pd}_{3} \mathrm{O}_{y}{ }^{+} \cdot \mathrm{Pd}_{3}{ }^{+}$adsorbs up to two oxygen molecules yielding $\mathrm{Pd}_{3} \mathrm{O}_{2}{ }^{+}$and $\mathrm{Pd}_{3} \mathrm{O}_{4}{ }^{+}$at room temperature. $\mathrm{Pd}_{3} \mathrm{O}_{4}{ }^{+}$represents the only product over a wide temperature range whereas at low temperatures $\mathrm{Pd}_{3} \mathrm{O}_{6}^{+}$and $\mathrm{Pd}_{3} \mathrm{O}_{8}^{+}$are detected as shown in Figure 5a. In contrast, $\mathrm{Pd}_{3} \mathrm{O}^{+}$does not react with $\mathrm{O}_{2}$ at room

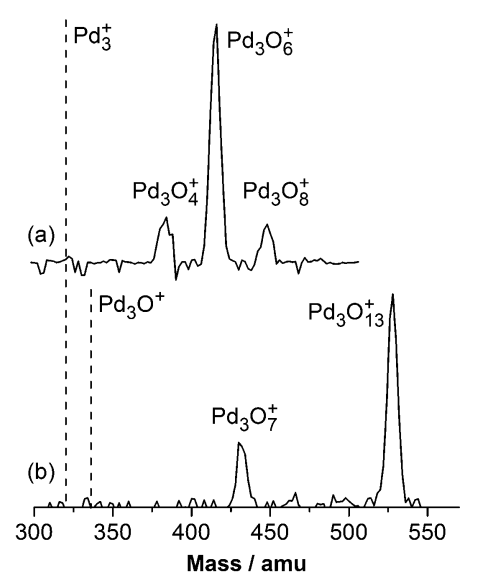

Figure 5. Mass spectra obtained after the reaction of (a) $\mathrm{Pd}_{3}{ }^{+}$and (b) $\mathrm{Pd}_{3} \mathrm{O}^{+}$with 0.10 and $0.05 \mathrm{~Pa} \mathrm{O}_{2}$, respectively, at $100 \mathrm{~K}$ (reaction time: $0.1 \mathrm{~s})$.

temperature but stable products are observed at temperatures below $230 \mathrm{~K}$ (Figures $3 \mathrm{~b}$ and $5 \mathrm{~b}$ ). Interestingly, only products of the stoichiometry $\mathrm{Pd}_{3} \mathrm{O}_{y+1}{ }^{+}$with $y=2,6,12$ are observed over the whole investigated temperature range whereas products with $y=4,8,10$ have not been detected. This indicates the particular stability of $\mathrm{Pd}_{3} \mathrm{O}_{3}{ }^{+}, \mathrm{Pd}_{3} \mathrm{O}_{7}{ }^{+}$, and $\mathrm{Pd}_{3} \mathrm{O}_{13}{ }^{+}$.

The theoretically predicted ground state structures of $\mathrm{Pd}_{3}{ }^{+}$ and $\mathrm{Pd}_{3} \mathrm{O}^{+}$as well as those of the experimentally observed oxidation products $\mathrm{Pd}_{x} \mathrm{O}_{2,4,6}{ }^{+}$and $\mathrm{Pd}_{x} \mathrm{O}_{3,7,13}{ }^{+}$are displayed in Figure $6 \mathrm{a}, \mathrm{b}$, respectively. The minimum energy structure of $\mathrm{Pd}_{3}{ }^{+}$is found to be a triangle in agreement with previous studies. ${ }^{42,43}$ On this triangle up to three oxygen molecules can bind molecularly with each $\mathrm{O}_{2}$ bridging two neighboring $\mathrm{Pd}$ atoms and thus one edge of the triangle yielding planar structures of $\mathrm{Pd}_{3} \mathrm{O}_{2}{ }^{+}, \mathrm{Pd}_{3} \mathrm{O}_{4}{ }^{+}$, and $\mathrm{Pd}_{3} \mathrm{O}_{6}{ }^{+}$with $\mathrm{O}_{2}$ adsorption energies amounting to $1.45,1.58$, and $2.37 \mathrm{eV}$, respectively. On the basis of these $\mathrm{O}_{2}$ binding energies, $\mathrm{Pd}_{3} \mathrm{O}_{6}{ }^{+}$should represent the dominant oxidation product over a wide temperature range in the experimental mass spectra which, however, is clearly not the case.

Figure 6a also shows that the molecularly bound $\mathrm{O}_{2}$ in $\mathrm{Pd}_{3} \mathrm{O}_{2}{ }^{+}$can dissociate, which results in a structure with the two $\mathrm{O}$ atoms each bridging two neighboring $\mathrm{Pd}$ atoms and thus bridging two edges of the triangle. The total adsorption energy

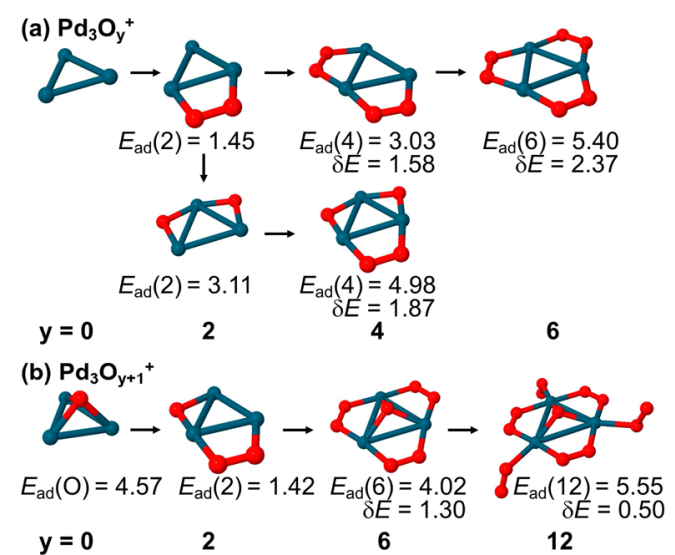

Figure 6. (a) Ground state and optimized isomeric structures of $\mathrm{Pd}_{3} \mathrm{O}_{y}^{+}, y=0,2,4,6$, and (b) ground state structures of $\mathrm{Pd}_{2} \mathrm{O}_{y+1}^{+}, y=$ $0,2,6,12$. All energies are in electronvolts. For the description of their derivation and the color code, please refer to Figure 4.

of these two atoms is $E_{\mathrm{ad}}(2)=3.11 \mathrm{eV}$, which consequently yields a structure energetically considerably more stable than the one comprising molecular oxygen. A second oxygen molecule is then bound molecularly $(\delta E=1.87 \mathrm{eV})$, bridging the remaining edge of the triangle, which results in an activated $\mathrm{O}_{2}$. This structure is also substantially lower in energy than the one containing only molecularly adsorbed oxygen, which is in perfect agreement with the experimentally observed particular stability of $\mathrm{Pd}_{3} \mathrm{O}_{4}{ }^{+}$over a wide temperature range. Furthermore, the dissociative oxygen adsorption also is in favorable agreement with the room temperature kinetic data, which are best described by a straightforward association reaction 1 , which indicates a strongly and potentially dissociatively bound first oxygen molecule (cf. section IIIA).

Our theoretical simulations predict a tetrahedral structure for $\mathrm{Pd}_{3} \mathrm{O}^{+}$with the oxygen atom forming one of the vertices bound by $E_{\mathrm{ad}}(\mathrm{O})=4.57 \mathrm{eV}$. The adsorption of a first oxygen molecule results in a structural rearrangement of the tetrahedron to form a structure with the oxygen atom and the $\mathrm{O}_{2}$ molecule each bridging one edge of a palladium triangle $\left(E_{\mathrm{ad}}(2)=1.42 \mathrm{eV}\right)$. In contrast, the adsorption of three $\mathrm{O}_{2}$ yields a more symmetric geometry consisting of a palladium triangle, capped with the single oxygen atom and each of the three edges of the triangle is bridged by one oxygen molecule $\left(\delta E=1.42 \mathrm{eV}\right.$ for the first $\mathrm{O}_{2}$ and $\delta E=1.30 \mathrm{eV}$ for each of the additional two $\mathrm{O}_{2}$ ). On each of the three $\mathrm{Pd}$ atoms one additional $\mathrm{O}_{2}$ can be terminally bound with about $\delta E=0.50 \mathrm{eV}$ yielding $\mathrm{Pd}_{3} \mathrm{O}_{13}{ }^{+}$. Thus, the particular symmetry of $\mathrm{Pd}_{3} \mathrm{O}_{7}{ }^{+}$and $\mathrm{Pd}_{3} \mathrm{O}_{13}{ }^{+}$might explain the observation of these products in the experimental mass spectra whereas the less symmetric $\mathrm{Pd}_{3} \mathrm{O}_{4,8,10}{ }^{+}$are not observed. Furthermore, the binding energies of these $\mathrm{O}_{2}$ molecules amounting to $1.42,1.30$, and $0.50 \mathrm{eV}$, respectively, are rather small compared to 3.11 and $1.87 \mathrm{eV}$ on $\mathrm{Pd}_{3} \mathrm{O}_{2}{ }^{+}$and $\mathrm{Pd}_{3} \mathrm{O}_{4}{ }^{+}$, which explains the lack of any oxidation products for $\mathrm{Pd}_{3} \mathrm{O}^{+}$at room temperature.

3. $\mathrm{Pd}_{4} \mathrm{O}_{y}^{+}$. Reaction of $\mathrm{Pd}_{4}^{+}$and $\mathrm{Pd}_{4} \mathrm{O}^{+}$with Molecular Oxygen. The room temperature reaction of the palladium tetramer $\mathrm{Pd}_{4}^{+}$and the singly oxidized $\mathrm{Pd}_{4} \mathrm{O}^{+}$with molecular oxygen results in the adsorption of two oxygen molecules yielding $\mathrm{Pd}_{4} \mathrm{O}_{4}{ }^{+}$and $\mathrm{Pd}_{4} \mathrm{O}_{5}{ }^{+}$, respectively, as shown in Figures $3 \mathrm{c}$ and $7 \mathrm{a}, \mathrm{b}$. In contrast, the preoxidized $\mathrm{Pd}_{4} \mathrm{O}_{2}^{+}$already containing two oxygen atoms only adsorbs one further oxygen 

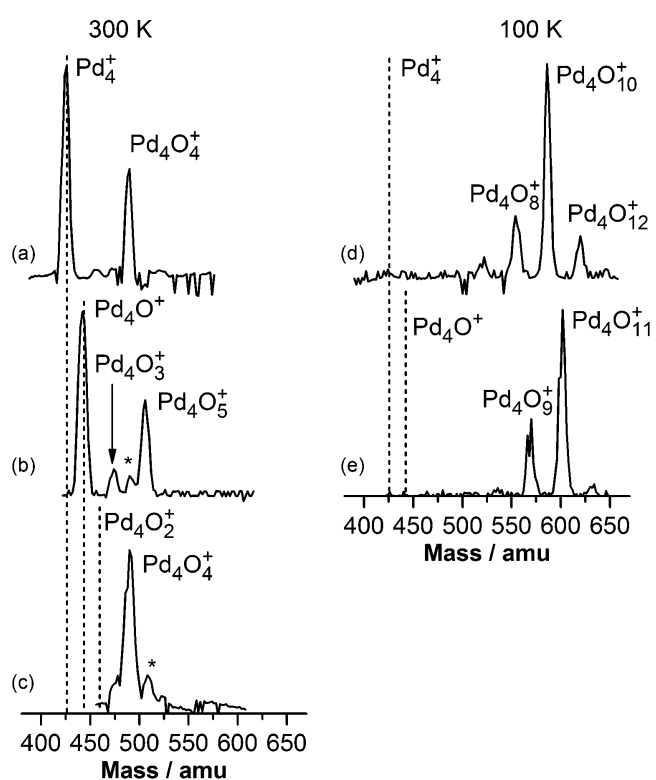

Figure 7. Mass spectra obtained after the reaction of (a, d) $\mathrm{Pd}_{4}{ }^{+}$ $\left(p\left(\mathrm{O}_{2}\right)=0.10 \mathrm{~Pa}\right),(\mathrm{b}, \mathrm{e}) \mathrm{Pd}_{4} \mathrm{O}^{+}\left(p\left(\mathrm{O}_{2}\right)=0.07 \mathrm{~Pa}\right)$, and $(\mathrm{c}) \mathrm{Pd}_{4} \mathrm{O}_{2}^{+}$ $\left(p\left(\mathrm{O}_{2}\right)=0.09 \mathrm{~Pa}\right)$ with $\mathrm{O}_{2}$ at $300 \mathrm{~K}$ (left column) and $100 \mathrm{~K}$ (right column) (reaction time: $0.1 \mathrm{~s}$ ). The minor products labeled with an asterisk are due to water impurities present in these particular experiments.

molecule to form $\mathrm{Pd}_{4} \mathrm{O}_{4}^{+}$, similar to the case of the bare cluster (cf. Figure 7c).

Cooling the ion trap to temperatures below $250 \mathrm{~K}$ leads to the adsorption of additional $\mathrm{O}_{2}$ molecules finally yielding $\mathrm{Pd}_{4} \mathrm{O}_{y}^{+}(y=8,10,12)$ and $\mathrm{Pd}_{4} \mathrm{O}_{y+1}{ }^{+}(y=8,10)$ at $100 \mathrm{~K}$, as displayed in Figure 7 d,e. These product distributions provide first indications that only a maximum number of five oxygen atoms can bind strongly to the $\mathrm{Pd}_{4}{ }^{+}$cluster whereas adsorption of further more weakly bound $\mathrm{O}_{2}$ molecules is only possible at lower reaction temperatures.

The measured temperature-dependent reaction profile of the palladium cation tetramer cluster is a most challenging one, but the corresponding reaction scheme of $\mathrm{Pd}_{4}{ }^{+}$with multiple $\mathrm{O}_{2}$ molecules, shown in Figure 8a, elucidates the experimental findings. The minimum energy structure of $\mathrm{Pd}_{4}^{+}$is a tetrahedron in agreement with a theoretical study by Kalita et al. ${ }^{43}$ whereas Efremenko and Sheintuch ${ }^{42}$ predicted a planar rectangular geometry. Starting with this bare tetrahedral cluster $\left(y=0\right.$ at the top left in Figure 8a), a single $\mathrm{O}_{2}$ molecule adsorbs nondissociatively with a rather low adsorption energy $E_{\mathrm{ad}}(2)=$ $0.64 \mathrm{eV}$. Nondissociative adsorption of further molecules may occur as exemplified for $\mathrm{Pd}_{4} \mathrm{O}_{4}^{+}(\delta E=1.08 \mathrm{eV})$ in Figure 8a which, however, cannot satisfactorily explain the experimental observation of $\mathrm{Pd}_{4} \mathrm{O}_{4}{ }^{+}$as the sole oxidation product and its particular stability at $T>250 \mathrm{~K}$.

On the other hand, activated dissociation of the first adsorbed molecule (with a transition state activation energy $\Delta E=0.70 \mathrm{eV})$, results in a lower energy $\mathrm{Pd}_{4} \mathrm{O}_{2}{ }^{+}$cluster $\left(E_{\mathrm{ad}}(2)\right.$ $=1.69 \mathrm{eV})$. Furthermore, this dissociative adsorption route may serve as a doorway to a sequence of (nondissociative) $\mathrm{O}_{2}$ adsorption processes, culminating with $\mathrm{Pd}_{4} \mathrm{O}_{10}{ }^{+}$; see middle row in Figure 8a. Most interestingly, for $\mathrm{Pd}_{4} \mathrm{O}_{4}{ }^{+}$the binding energy of the second, nondissociatively adsorbed but activated $\mathrm{O}_{2}$ molecule is predicted to be particularly high, $\delta E=2.12 \mathrm{eV}$ whereas $\mathrm{Pd}_{4} \mathrm{O}_{y}{ }^{+}$clusters with $y=6,8,10$ are predicted to have low $\delta E$ values, i.e., $\delta E=0.68,0.74$, and $0.18 \mathrm{eV}$, respectively.

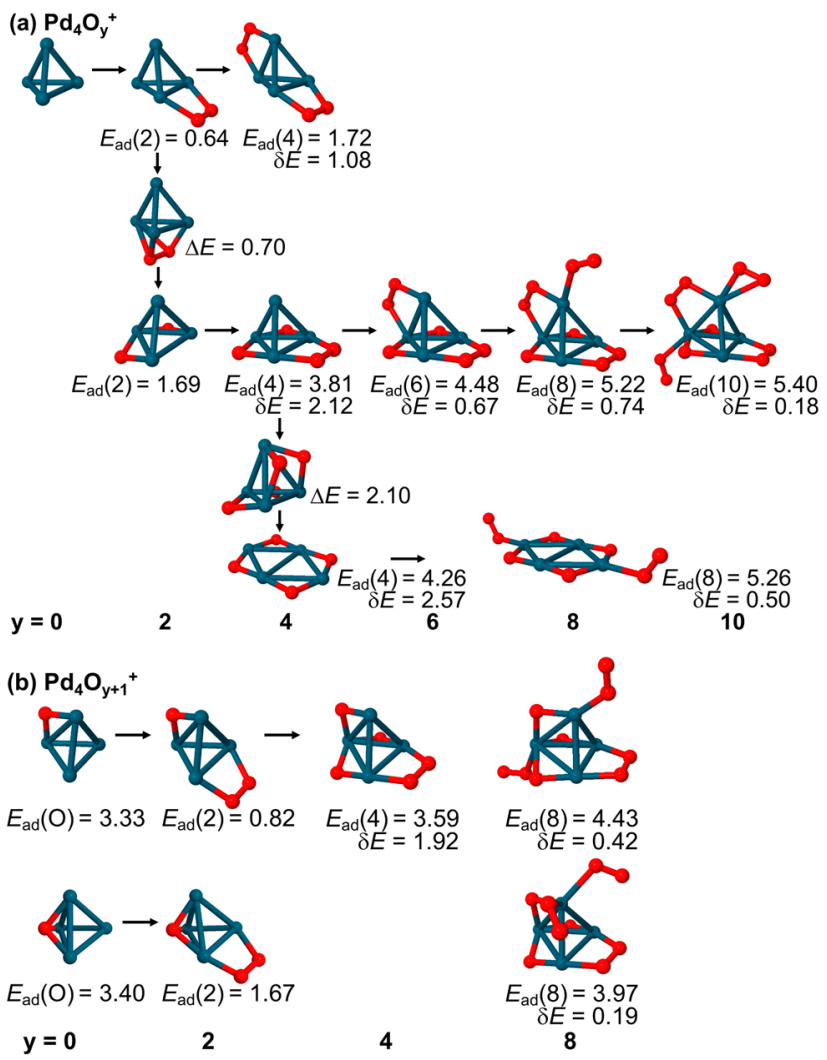

Figure 8. Ground state and optimized isomeric structures of (a) $\mathrm{Pd}_{4} \mathrm{O}_{y}{ }^{+}, y=0,2,4,6,8,10$, and (b) $\mathrm{Pd}_{4} \mathrm{O}_{y+1}{ }^{+}, y=0,2,4,8$. For the definition of the energies and the color code, please refer to Figure 4. In the case of structural changes (dissociation or dimensionality transformation) the transition state and the corresponding energy barrier $\Delta E$ are displayed.

This finding clearly demonstrates an enhanced stability of $\mathrm{Pd}_{4} \mathrm{O}_{4}{ }^{+}$, which agrees perfectly with the experimental observation of $\mathrm{Pd}_{4} \mathrm{O}_{4}{ }^{+}$as the sole product in the temperature range of $300 \mathrm{~K} \leq T \leq 250 \mathrm{~K}$ as well as the adsorption of multiple more weakly bound $\mathrm{O}_{2}$ molecules only at lower temperatures.

Additionally, the small binding energy of the first oxygen molecule amounting to $0.64 \mathrm{eV}$ and the activation barrier of 0.7 $\mathrm{eV}$ for oxygen dissociation is in favorable agreement with the experimental kinetic data, which yield a non-negligible rate constant $k_{-1}$ for the back-reaction in eq 4 . This already indicated a weak molecular adsorption of a first $\mathrm{O}_{2}$ and/or activation barriers for dissociation and formation of more stable $\mathrm{Pd}_{x} \mathrm{O}_{y}{ }^{+}$. A rough RRKM estimation based on the determined $k_{1}$ value also yields a binding energy of a first $\mathrm{O}_{2}$ to $\mathrm{Pd}_{4}{ }^{+}$of $\sim 0.7$ $\mathrm{eV}$.

A further alternative pathway is depicted in the bottom row of Figure 8a showing a dimensionality-reducing activated dissociation of the second adsorbed $\mathrm{O}_{2}$ molecule. Although this results in a planar $\mathrm{Pd}_{4} \mathrm{O}_{4}{ }^{+}$structure with even lower total energy, the activation barrier for the structural rearrangement is rather high, $\Delta E=2.10 \mathrm{eV}$, which is difficult to overcome in particular at low temperatures. Further $\mathrm{O}_{2}$ molecules are then weakly bound $(\delta E=0.50 \mathrm{eV})$ on this cluster as exemplified for $\mathrm{Pd}_{4} \mathrm{O}_{8}^{+}$.

The results of our theoretical simulations for the oxidation products of $\mathrm{Pd}_{4} \mathrm{O}^{+}$are displayed in Figure $8 \mathrm{~b}$. Two isomeric structures for $\mathrm{Pd}_{4} \mathrm{O}^{+}$have been found with the oxygen atom in 
a $\mu_{2}$-bridging (binding energy of the oxygen atom $E_{\mathrm{ad}}(\mathrm{O})=$ $3.33 \mathrm{eV})$ and a $\mu_{3}$-bridging position $\left(E_{\mathrm{ad}}(\mathrm{O})=3.40 \mathrm{eV}\right)$, respectively. Adsorption of a first oxygen molecule can occur molecularly on both structures with $E_{\mathrm{ad}}(2)=0.82 \mathrm{eV}$ and $E_{\mathrm{ad}}(2)=1.67 \mathrm{eV}$. In the case of the adsorption of a second oxygen molecules, however, dissociation of one of the adsorbed oxygen molecules is predicted to occur, leading to the most stable structure of $\mathrm{Pd}_{4} \mathrm{O}_{5}{ }^{+}\left(E_{\mathrm{ad}}(4)=3.59 \mathrm{eV}\right)$. Further oxygen molecules are then bound terminally with considerably lower adsorption energies of 0.42 and $0.19 \mathrm{eV}$ depending on the binding site as exemplified for $\mathrm{Pd}_{4} \mathrm{O}_{9}{ }^{+}$in Figure, 8b. These adsorption energies correlate well with the experimental observations pertaining to the particular stability of $\mathrm{Pd}_{4} \mathrm{O}_{5}{ }^{+}$at temperatures between 300 and $250 \mathrm{~K}$ and the adsorption of further weakly bound $\mathrm{O}_{2}$ at lower temperatures.

Bonding Mechanism of $\mathrm{O}_{2}$ to Palladium Clusters. To gain insight into the nature of interaction between palladium clusters and oxygen, the electronic density of states (DOS) has been investigated theoretically using the example of $\mathrm{Pd}_{4}{ }^{+}$. Figure 9

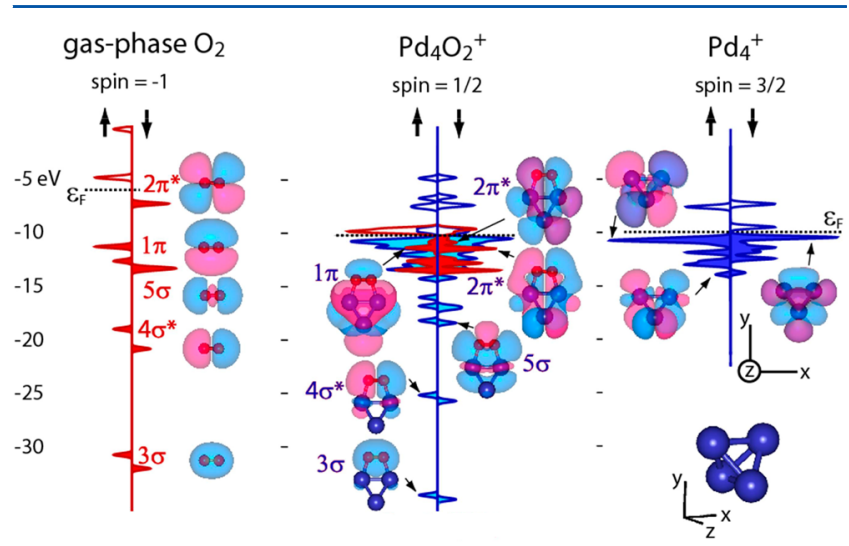

Figure 9. Electronic structure, represented by the density of states (DOS) and isosurfaces (encompassing $90 \%$ of the electron density) of selected orbitals (with positive and negative values depicted in blue and pink, respectively) for a gas phase $\mathrm{O}_{2}$ molecule (left), an isolated $\mathrm{Pd}_{4}{ }^{+}$cluster (right), and a $\mathrm{Pd}_{4} \mathrm{O}_{2}{ }^{+}$complex (middle). The DOS is shown separately for up and down electrons and the occupied states (i.e., states with energy below $\varepsilon_{\mathrm{F}}$ ) are shown as filled features on the energy axis. The Fermi level, $\varepsilon_{\mathrm{F}}$, is denoted by a dashed line, and features on the energy axis denoting a double-degeneracy of the spinorbital (leading to a maximum double occupancy of that degenerate eigenvalue) are twice as long as those corresponding to nondegenerate spin orbitals (single occupancy). The overlap of the antibonding $2 \pi^{*}$ orbitals with the cluster wave function $\Psi(\varepsilon)$ given by $\Sigma_{2 \pi^{*}}\left\langle 2 \pi^{*} \mid \Psi(\varepsilon)\right\rangle^{2}$ (scaled by a factor of 7.5 for visualization) is shown for the $\mathrm{Pd}_{4} \mathrm{O}_{2}{ }^{+}$ complex by red filled peaks superimposed on the DOS. The tetrahedral structure of the palladium tetramer cation is shown at the bottom right, and the viewpoint of the cluster used for displaying the orbitals of the bare cluster and the complex is indicated by the rotated coordinate system shown at the bottom of the DOS on the right. More details are given in the text.

displays the DOS for an isolated $\mathrm{Pd}_{4}{ }^{+}$cluster (right), a free $\mathrm{O}_{2}$ molecule (left), and a $\mathrm{Pd}_{4} \mathrm{O}_{2}{ }^{+}$complex (middle). The DOS of gas phase $\mathrm{O}_{2}$, together with isosurfaces of the corresponding molecular orbitals, show that the spin-down antibonding $2 \pi^{*}$ orbital is occupied, while the spin-up $2 \pi^{*}$ is empty. Because there are (two) degenerate, $2 \pi_{x}^{*}$ and $2 \pi_{y}^{*}$, orbitals, the total occupation of the spin down $2 \pi^{*}$ is $f\left(2 \pi^{*} ; \downarrow\right)=2$. The groundstate molecule is paramagnetic, with an $\mathrm{O}-\mathrm{O}$ bond-length $d(\mathrm{O}-\mathrm{O})=1.25 \AA$.
On the right side of Figure 9 the DOS with $-6.5 \mathrm{eV} \geq E \geq$ $-14.5 \mathrm{eV}$ of the energy optimized free tetrahedral $\mathrm{Pd}_{4}{ }^{+}$are shown along with some of the highest occupied orbitals (lying below the Fermi level $\varepsilon_{\mathrm{F}}$ ). These states exhibit mostly d-like character whereas $\mathrm{p}$ and $\mathrm{s}$ states are at energies of $-58 \mathrm{eV} \geq E$ $\geq-60 \mathrm{eV}$ and $-92 \mathrm{eV}$, respectively (not shown in the figure). The DOS of $\mathrm{Pd}_{4}^{+}$show some (small) differences in the DOS of up and down spins reflecting a nonzero spin magnetization of the cluster cation.

The DOS and selected isosurfaces of the cluster orbitals, displayed in the middle of Figure 9, illustrate modifications to the electronic structure of the interaction partners $\left(\mathrm{O}_{2}\right.$ and $\mathrm{Pd}_{4}^{+}$) caused by the formation of the bonded complex $\mathrm{Pd}_{4} \mathrm{O}_{2}{ }^{+}$, with the $\varepsilon_{\mathrm{F}}$ of the latter lying close to that of the isolated palladium tetramer cation and below that of the free $\mathrm{O}_{2}$ molecule. Orbitals at the bottom of the DOS spectrum resemble closely those of the free $\mathrm{O}_{2}$ molecule. On the other hand, starting with the $5 \sigma$ orbital (and for higher-energy levels) the orbitals of the $\mathrm{O}_{2}$ molecule are mixed with those of the $\mathrm{Pd}_{4}{ }^{+}$ cluster.

The adsorption of the $\mathrm{O}_{2}$ molecule on the palladium tetramer cation shifts and broadens the unoccupied $2 \pi^{*}$ (spinup component) downward, so that part of it is pulled to values lying below the Fermi level, leading to its partial occupation. This reduces the magnetic moment of the adsorbed $\mathrm{O}_{2}$ molecule (compared to the paramagnetic free molecule); a similar mechanism has been described for the bonding and activation of $\mathrm{O}_{2}$ and $\mathrm{CO}$ molecules on magnesia-supported gold clusters $^{44-46}$ (see also Figure 1.78 in ref 15 ).

The quantification of this activation mechanism entails the evaluation of the squared value of the overlap integral of the $2 \pi^{*}$ orbitals of the oxygen molecule with the cluster wave functions $\Psi(\varepsilon)$ according to $\sum_{2 \pi^{*}}\left\langle 2 \pi^{*} \mid \Psi(\varepsilon)\right\rangle^{2}$, which is shown by the red areas in the DOS below $\varepsilon_{\mathrm{F}}$ (Figure 9, middle). When this squared overlap is integrated over the energy, $\mathrm{d} \varepsilon$ $f(\varepsilon) \sum_{2 \pi^{*}}\left\langle 2 \pi^{*} \mid \Psi(\varepsilon)\right\rangle^{2}$, a value of 2.6 is obtained compared to a value of 2.0 calculated for the free $\mathrm{O}_{2}$ molecule. This indicates increased occupancy of the antibonding component of $\Psi$ due to transfer of electronic charge in the amount of $0.6 \mathrm{e}$ from the palladium cluster to the adsorbed oxygen molecule. This results in a larger $\mathrm{d}(\mathrm{O}-\mathrm{O})$ distance $(1.33 \AA)$ in the superoxo activated adsorbed molecule.

4. $\mathrm{Pd}_{5} \mathrm{O}_{y}^{+} / \mathrm{Pd}_{6} \mathrm{O}_{y}^{+}$. The five and six atom palladium clusters and their oxides show quite similar reaction behaviors. $\mathrm{Pd}_{5}{ }^{+}$and $\mathrm{Pd}_{5} \mathrm{O}^{+}$strongly adsorb two oxygen molecules at room temperature (cf. Figure 3d), forming $\mathrm{Pd}_{5} \mathrm{O}_{4}{ }^{+}$and $\mathrm{Pd}_{5} \mathrm{O}_{5}{ }^{+}$, respectively, whereas the preoxidized $\mathrm{Pd}_{5} \mathrm{O}_{2}^{+}$only adsorbs one $\mathrm{O}_{2}$ to form $\mathrm{Pd}_{5} \mathrm{O}_{4}{ }^{+}$(not shown here). These complexes appear to be particularly stable and inert toward further oxidation with $\mathrm{O}_{2}$ over a wide temperature range and only adsorb additional oxygen at temperatures as low as $130 \mathrm{~K}$ resulting in $\mathrm{Pd}_{5} \mathrm{O}_{y}{ }^{+}(y=$ $6,8,10,12)$ and $\mathrm{Pd}_{5} \mathrm{O}_{y+1}{ }^{+}(y=10,12,14)$.

Similarly, $\mathrm{Pd}_{6}^{+}$and $\mathrm{Pd}_{6} \mathrm{O}^{+}$react with two oxygen molecules at room temperature (cf. Figure $3 \mathrm{e}$ ) yielding $\mathrm{Pd}_{6} \mathrm{O}_{4}^{+}$and $\mathrm{Pd}_{6} \mathrm{O}_{5}{ }^{+}$, respectively, whereas $\mathrm{Pd}_{6} \mathrm{O}_{2}{ }^{+}$forms $\mathrm{Pd}_{6} \mathrm{O}_{4}{ }^{+}$(Figure $10 \mathrm{a}-\mathrm{c})$. Further oxygen adsorption is only observed at temperatures below about $140 \mathrm{~K}$ leading to the formation of $\mathrm{Pd}_{6} \mathrm{O}_{y}{ }^{+}(y=6,8,10,12)$ and $\mathrm{Pd}_{6} \mathrm{O}_{y+1}{ }^{+}(y=6,8,10,12,14)$, as can be seen from Figure 10d,e. These experimental observations are comparable to the findings for $\mathrm{Pd}_{4}^{+}$in the sense that they indicate the strong adsorption of a maximum of at most five oxygen atoms on the palladium cluster cations and 


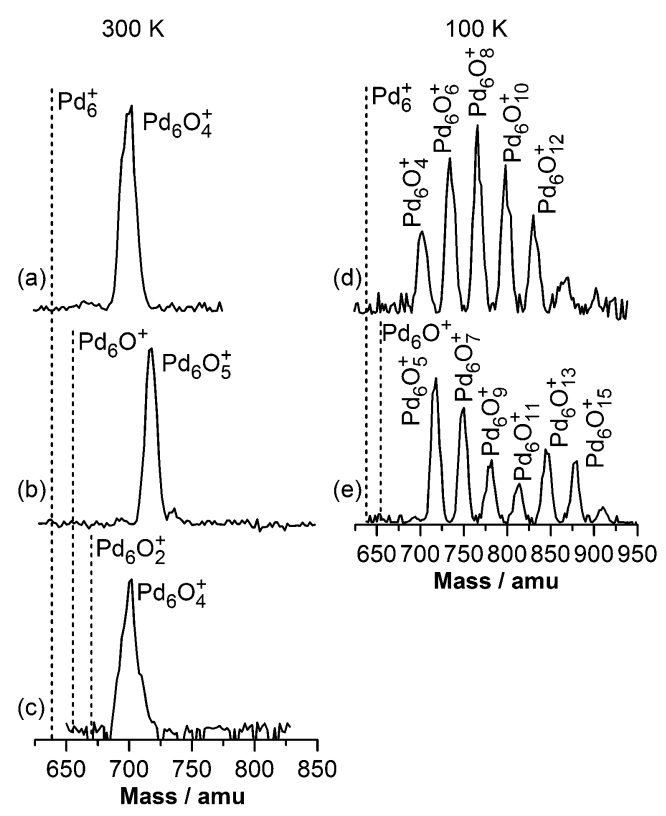

Figure 10. Mass spectra obtained after the reaction of (a, d) $\mathrm{Pd}_{6}{ }^{+}$ $\left(p\left(\mathrm{O}_{2}\right)=0.10 \mathrm{~Pa}\right),(\mathrm{b}, \mathrm{e}) \mathrm{Pd}_{6} \mathrm{O}^{+}\left(p\left(\mathrm{O}_{2}\right)=0.07 \mathrm{~Pa}\right)$, and $(\mathrm{c}) \mathrm{Pd}_{6} \mathrm{O}_{2}^{+}$ $\left(p\left(\mathrm{O}_{2}\right)=0.09 \mathrm{~Pa}\right)$ with $\mathrm{O}_{2}$ at $300 \mathrm{~K}$ (left column) and $100 \mathrm{~K}$ (right column).

a second, weakly bound oxygen species occurring at cryogenic temperatures.

$\mathrm{Pd}_{6}{ }^{+}$is found to have an octahedral geometry as displayed in Figure 11a in agreement with previous DFT calculations, ${ }^{43}$

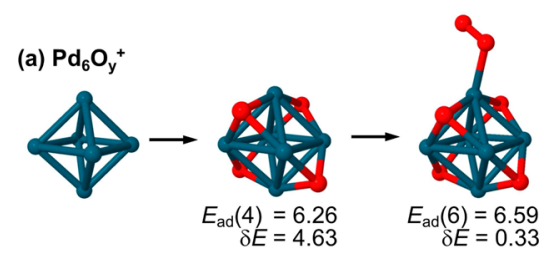

(b) $\mathrm{Pd}_{6} \mathrm{O}_{\mathrm{y}+1}{ }^{+}$

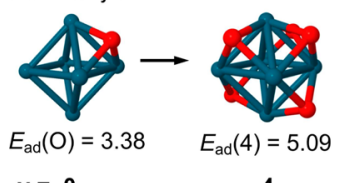

$y=0$

Figure 11. Ground state atomic structures of (a) $\mathrm{Pd}_{6} \mathrm{O}_{y}^{+}, y=0,4,6$, and (b) $\mathrm{Pd}_{6} \mathrm{O}_{y+1}{ }^{+}, y=0$, 4. All energies are in electronvolts. For the description of their derivation and the color code, please refer to Figure 4.

whereas a planar structure had been predicted on the basis of the extended Hückel method. ${ }^{42}$ Our theoretical simulations reveal facile dissociation of two oxygen molecules resulting in an oxidized cluster with each oxygen bonded to three neighboring $\mathrm{Pd}$ atoms in $\mathrm{Pd}_{6} \mathrm{O}_{4}{ }^{+}$and a total adsorption energy of $E_{\text {ad }}(4)=6.26 \mathrm{eV}$. A third oxygen molecule binds molecularly with an adsorption energy of $\delta E=0.33 \mathrm{eV}$, which is significantly lower than the binding of the first $(\delta E=1.63$ $\mathrm{eV})$ and second $(\delta E=4.63 \mathrm{eV})$ dissociatively adsorbed molecule in $\mathrm{Pd}_{6} \mathrm{O}_{4}{ }^{+}$. These adsorption energies agree well with the experimentally observed preferred formation of the tetraoxide cluster and its resistance to further oxidation in a wide temperature range. Furthermore, the dissociation of the first oxygen molecule correlates well with the kinetic data, which are best fit by an association reaction 1 , indicating strong and potentially dissociative adsorption of a first $\mathrm{O}_{2}$ molecule (cf. section IIIA).

Figure $11 \mathrm{~b}$ displays the ground state structure of the singly oxidized $\mathrm{Pd}_{6} \mathrm{O}^{+}$, showing the coordination of the oxygen atom to three palladium atoms with a binding energy of $3.38 \mathrm{eV}$. Adsorption of two oxygen atoms results in facile dissociation of both molecules leading to a structure comprising five strongly adsorbed $\left(E_{\mathrm{ad}}(4)=5.09 \mathrm{eV}\right)$ oxygen atoms each bonded to three neighboring $\mathrm{Pd}$ atoms.

5. $\mathrm{Pd}_{7} \mathrm{O}_{y}^{+}$. Figure 12 displays room temperature ion mass distributions obtained after reaction of $\mathrm{Pd}_{7}^{+}$(trace a) as well as

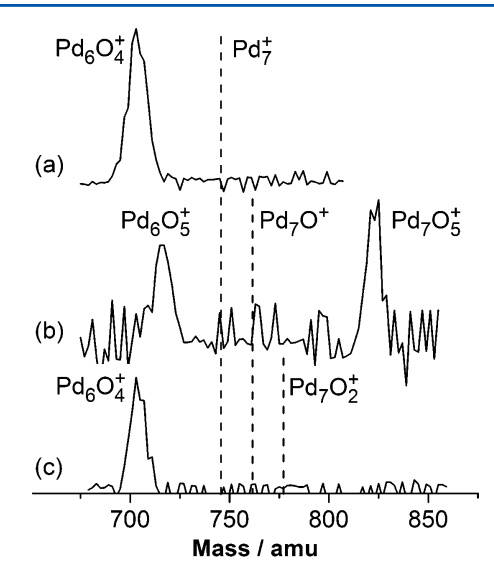

Figure 12. Mass spectra obtained after the reaction of $(\mathrm{a}) \mathrm{Pd}_{7}^{+}\left(p\left(\mathrm{O}_{2}\right)\right.$ $=0.07 \mathrm{~Pa}),(\mathrm{b}) \mathrm{Pd}_{7} \mathrm{O}^{+}\left(p\left(\mathrm{O}_{2}\right)=0.08 \mathrm{~Pa}\right)$, and $(\mathrm{c}) \mathrm{Pd}_{7} \mathrm{O}_{2}{ }^{+}\left(p\left(\mathrm{O}_{2}\right)=\right.$ $0.08 \mathrm{~Pa})$ with $\mathrm{O}_{2}$ at room temperature illustrating the complete fragmentation of $\mathrm{Pd}_{7}^{+}$and $\mathrm{Pd}_{7} \mathrm{O}_{2}^{+}$into the stable product $\mathrm{Pd}_{6} \mathrm{O}_{4}^{+}$ whereas $\mathrm{Pd}_{7} \mathrm{O}^{+}$only partially fragments to yield $\mathrm{Pd}_{6} \mathrm{O}_{5}{ }^{+}$.

the preoxidized clusters $\mathrm{Pd}_{7} \mathrm{O}^{+}$(trace $\mathrm{b}$ ) and $\mathrm{Pd}_{7} \mathrm{O}_{2}{ }^{+}$(trace $\mathrm{c}$ ) with molecular oxygen. Most interestingly, $\mathrm{Pd}_{7}^{+}$and $\mathrm{Pd}_{7} \mathrm{O}_{2}{ }^{+}$ completely fragment into the stable product $\mathrm{Pd}_{6} \mathrm{O}_{4}{ }^{+}$whereas for $\mathrm{Pd}_{7} \mathrm{O}^{+}$both a fragmentation product $\mathrm{Pd}_{6} \mathrm{O}_{5}^{+}$and an adsorption product $\mathrm{Pd}_{7} \mathrm{O}_{5}{ }^{+}$are detected. The preferred fragmentation of the palladium septamer and its oxides supports the particular stability of the $\mathrm{Pd}_{6} \mathrm{O}_{4}^{+}$and $\mathrm{Pd}_{6} \mathrm{O}_{5}^{+}$, respectively, as discussed above.

This particular stability of the highly symmetric $\mathrm{Pd}_{6} \mathrm{O}_{4}{ }^{+}$is additionally supported by the fragmentation mechanism of $\mathrm{Pd}_{7}^{+}$ shown in Figure 13a. Similar to $\mathrm{Pd}_{6}^{+}$the first two oxygen atoms

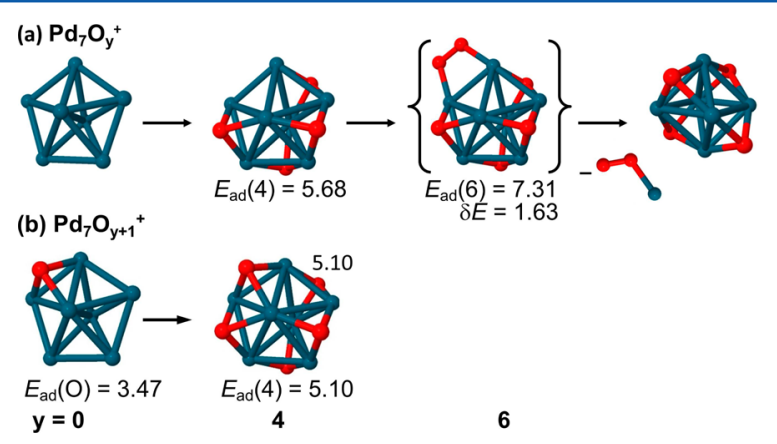

Figure 13. Ground state atomic structures of $(\mathrm{a}) \mathrm{Pd}_{7} \mathrm{O}_{y}^{+}, y=0,4,6$, and (b) $\mathrm{Pd}_{7} \mathrm{O}_{y+1}{ }^{+}, y=0,4$. The structure in curly brackets depicts a (nonobservable) transient intermediate. For the energy calculations and the color code, please refer to Figure 4. 
can easily dissociate on the seven-atom cluster yielding $\mathrm{Pd}_{7} \mathrm{O}_{4}{ }^{+}$ with each oxygen atom coordinated to three palladium atoms and a total adsorption energy of $E_{\text {ad }}(4)=5.68 \mathrm{eV}$. The third $\mathrm{O}_{2}$ is adsorbed molecularly (with $\delta E=1.63 \mathrm{eV}$ ), resulting in formation of a transient (nonobservable) intermediate $\mathrm{Pd}_{7} \mathrm{O}_{6}^{+}$ (cf. configuration in curly brackets in Figure 13a). A $\mathrm{PdO}_{2}$ molecule then evaporates from the $\mathrm{Pd}_{7} \mathrm{O}_{6}^{+}$intermediate yielding the stable $\mathrm{Pd}_{6} \mathrm{O}_{4}{ }^{+}$.

In contrast, the singly oxidized $\mathrm{Pd}_{7} \mathrm{O}^{+}$only partially fragments into $\mathrm{Pd}_{6} \mathrm{O}_{5}{ }^{+}$besides formation of $\mathrm{Pd}_{7} \mathrm{O}_{5}^{+}$, indicating a partial stabilization of the palladium septamer by a single oxygen atom. The calculated structure of $\mathrm{Pd}_{7} \mathrm{O}^{+}\left(E_{\mathrm{ad}}(\mathrm{O})=3.47\right.$ $\mathrm{eV}$ ) is displayed in Figure 13b. Two oxygen atoms are dissociatively adsorbed on $\mathrm{Pd}_{7} \mathrm{O}^{+}$with $E_{\mathrm{ad}}(4)=5.10 \mathrm{eV}$. Adsorption of an $\mathrm{O}_{2}$ molecule on $\mathrm{Pd}_{7} \mathrm{O}_{5}{ }^{+}$to form a fragmentation-intermediate (similar to the one for $\mathrm{Pd}_{7} \mathrm{O}_{6}{ }^{+}$, Figure 13a) is hindered by the extra adsorbed oxygen atom, thus partially closing the fragmentation channel.

6. $\mathrm{Pd}_{8} \mathrm{O}_{y}^{+}$. Finally, for the case of clusters with eight palladium atoms, the reaction with oxygen could only be measured for $\mathrm{Pd}_{8} \mathrm{O}^{+}$. The result is displayed in Figure $3 \mathrm{~g}$. In accordance with the data obtained for the smaller cluster sizes, the oxidation is self-limiting. In this case $\mathrm{Pd}_{8} \mathrm{O}^{+}$reacts immediately with three $\mathrm{O}_{2}$ molecules and the resulting complex $\mathrm{Pd}_{8} \mathrm{O}_{7}^{+}$does not adsorb further oxygen over the whole investigated temperature range.

Figure 14 shows that the $\mathrm{Pd}_{8}{ }^{+}$cluster is an octahedron with adjacent faces capped (lower left structure in Figure 14). The

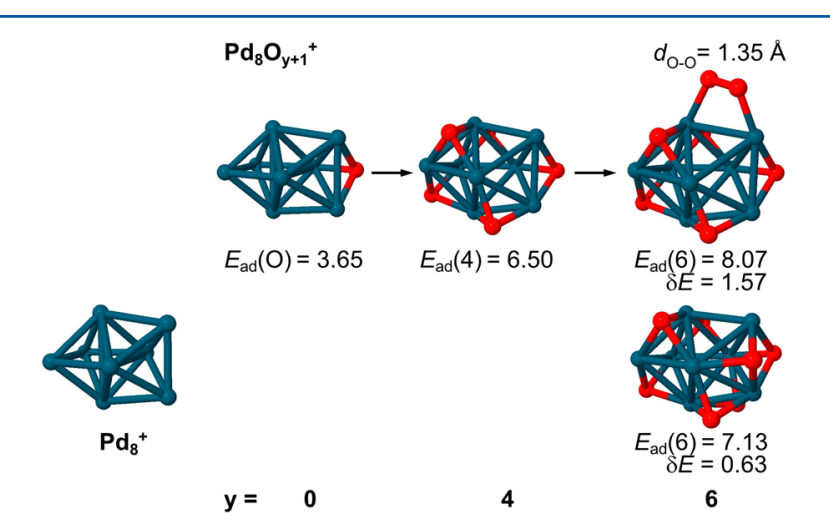

Figure 14. Ground state structures of $\mathrm{Pd}_{8} \mathrm{O}_{y+1}{ }^{+}, y=0,4,6$. For $\mathrm{Pd}_{8} \mathrm{O}_{7}{ }^{+}$ a higher energy isomeric structure containing only dissociated oxygen is depicted as well. At the lower left the optimal structure of the bare $\mathrm{Pd}_{8}{ }^{+}$cluster is shown. All energies are in electronvolts. For the description of their derivation and the color code, please refer to Figure 4.

first $\mathrm{O}$ atom binds to a face of the cluster with a binding energy of $3.65 \mathrm{eV}$. All face sites are about equivalent. Two further $\mathrm{O}_{2}$ molecules bind dissociatively to other nonadjacent faces finally, leaving no more open faces that do not have an adjacent $\mathrm{O}$ atom. The third $\mathrm{O}_{2}$ molecule molecularly binds in a bridge position. The most favorable is likely the one shown in the upper row of Figure 14. It has the most acute angle between the adjacent faces and one of the $\mathrm{Pd}$ atoms has one (rather than two) O neighbors. This molecularly bound $\mathrm{O}_{2}$ is "activated" with a bond length of $1.35 \AA$. If this third $\mathrm{O}_{2}$ molecule dissociates, the atoms must go to faces which have adjacent $\mathrm{O}$ atoms already. However, the binding energy is considerably less than in the molecularly adsorbed case (cf. lower rightmost structure in Figure 14).

\section{SUMMARY AND CONCLUSIONS}

The temperature-dependent reactions of small palladium clusters $\mathrm{Pd}_{x}^{+}(x=2-7)$ and its oxides $\mathrm{Pd}_{x} \mathrm{O}^{+}(x=2-8)$ and $\mathrm{Pd}_{x} \mathrm{O}_{2}^{+}(x=4-7)$ with molecular oxygen reveal the formation of two different oxygen species. The fast adsorption of up to two oxygen molecules (three $\mathrm{O}_{2}$ for $\mathrm{Pd}_{8} \mathrm{O}^{+}$) yielding $\mathrm{Pd}_{x} \mathrm{O}_{4}^{+}$ (for $\mathrm{Pd}_{x}^{+}, x=2-7$ ), $\mathrm{Pd}_{x} \mathrm{O}_{5}^{+}$(for $\mathrm{Pd}_{x} \mathrm{O}^{+}, x=2,4-7$ ), and $\mathrm{Pd}_{8} \mathrm{O}_{7}^{+}$, respectively, and the resistance of these complexes (self-limiting oxidation) to further oxidation in a large temperature range indicates strongly bound chemisorption of the first two $\mathrm{O}_{2}$ molecules. Further, $\mathrm{O}_{2}$ molecules are found to be only adsorbed at low temperatures pointing toward molecularly physisorbed oxygen.

Dissociative chemisorption of oxygen was also found on supported palladium nanoparticles at temperatures below 450 $\mathrm{K}^{47}$ in line with the observations reported here for the free palladium clusters. Furthermore, although the initial sticking probability of oxygen on the supported Pd particles is high, it was observed to decrease to a very low value as the chemisorbed oxygen layer approached saturation, which also resembles the self-limiting oxidation described here for the very small free clusters.

Complementary theoretical first-principles simulations of the experimentally observed products provide molecular level insights into the interaction between palladium clusters and molecular oxygen and the quantum-chemical principles underlying the bonding and dissociation of oxygen molecules on palladium clusters. The self-limiting behavior illustrated above may be summarized as follows: Small palladium clusters adsorb strongly only a limited (maximal) number $\left(N_{\mathrm{O}, \max }\right)$ of oxygen molecules in an activated molecular configuration where each $\mathrm{O}_{2}$ molecule bridges between two neighboring $\mathrm{Pd}$ atoms. Dissociation of these activated molecules leads to formation of oxidized clusters with each oxygen bonded to several (two or three) neighboring $\mathrm{Pd}$ atoms. $\mathrm{Pd}_{x} \mathrm{O}_{y}{ }^{+}$and $\mathrm{Pd}_{x} \mathrm{O}_{y+1}{ }^{+}$complexes comprising such strongly adsorbed and activated molecules and/or atoms are the ones detected at higher temperatures, e.g., room temperature.

Further interaction of oxygen molecules with the self-limiting oxidized cluster (i.e., $\mathrm{Pd}_{x} \mathrm{O}_{y}^{+}$and $\mathrm{Pd}_{x} \mathrm{O}_{y+1}{ }^{+}, y=N_{\text {O,max }}=4$ for $x$ $=2-7$, and $y=6$ for $x=8$ ) results in weak molecularly adsorbed states. These molecules contribute to the low temperature mass spectrometric signals.

Thus, the self-limiting nature appears to originate from the inability of $\mathrm{Pd}$ atoms of the cluster to bind strongly to more than two oxygen atoms. That is, binding of $\mathrm{O}_{2}$ to an already double-oxygen-coordinated $\mathrm{Pd}$ atom results in a weakly adsorbed molecular state. Additionally, dissociation of adsorbed molecules above the self-limiting number is inhibited due to site blocking by the already-adsorbed oxygen atoms.

\section{AUTHOR INFORMATION}

\section{Corresponding Authors}

*T. M. Bernhardt: fax, (+49) 731-50-25452; tel, (+49) 731-5025455; e-mail, thorsten.bernhardt@uni-ulm.de.

*U. Landman: fax, (+1)404-894-7747; tel, (+1)404-894-3368; e-mail, uzi.landman@physics.gatech.edu.

\section{Notes}

The authors declare no competing financial interest. 


\section{ACKNOWLEDGMENTS}

We gratefully acknowledge financial support by the Deutsche Forschungsgemeinschaft. In particular, S.M.L. is grateful to the European Social Fund Baden-Württemberg for a Margarete von Wrangell fellowship. The work of U.L. and R.N.B. at the Georgia Institute of Technology was supported by a grant from the U.S. Air Force Office of Scientific Research (AFOSR), with partial support to U.L. by the Office of Basic Energy Sciences of the U.S. Department of Energy under Contract No. FG0586ER45234. Computations were made at the GATECH Center for Computational Materials Science.

\section{REFERENCES}

(1) Croft, L. Nobel Prize 2010: Prestige for Palladium. Nat. Chem. 2010, 2, 1009-1009.

(2) Gandhi, H. S.; Graham, G. W.; McCabe, R. W. Automotive Exhaust Catalysis. J. Catal. 2003, 216, 433-442.

(3) Anderson, R. B.; Stein, K. C.; Feenan, J. J.; Hofer, L. J. E. Catalytic Oxidation of Methane. Ind. Eng. Chem. 1961, 53, 809-812. (4) Schalow, T.; Brandt, B.; Laurin, M.; Schauermann, S.; Libuda, J.; Freund, H.-J. CO Oxidation on Partially Oxidized Pd Nanoparticles. J. Catal. 2006, 242, 58-70.

(5) Lundgren, E.; Kresse, G.; Klein, C.; Borg, M.; Andersen, J. N.; De Santis, M.; Gauthier, Y.; Konvicka, C.; Schmid, M.; Varga, P. TwoDimensional Oxide on Pd(111). Phys. Rev. Lett. 2002, 88, 246103.

(6) Zemlyanov, D.; Aszalos-Kiss, B.; Kleimenov, E.; Teschner, D.; Zafeiratos, S.; Hävecker, M.; Knop-Gericke, A.; Schlögl, R.; Gabasch, H.; Unterberger, W.; Hayek, K.; Klötzer, B. In situ XPS Study of $\mathrm{Pd}(111)$ Oxidation. Part 1:2D oxide formation in $10^{-3} \mathrm{mbar}_{2}$. Surf. Sci. 2006, 600, 983-994.

(7) Gabasch, H.; Knop-Gericke, A.; Schlögl, R.; Borasio, M.; Weilach, C.; Rupprechter, G.; Penner, S.; Jenewein, B.; Hayek, K.; Klötzer, B. Comparison of the Reactivity of Different Pd-O Species in CO oxidation. Phys. Chem. Chem. Phys. 2007, 9, 533-540.

(8) Schalow, T.; Laurin, M.; Brandt, B.; Schauermann, S.; Guimond, S.; Kuhlenbeck, H.; Starr, D. E.; Shaikhutdinov, S. K.; Libuda, J.; Freund, H.-J. Oxygen Storage at the Metal/Oxide Interface of Catalyst Nanoparticles. Angew. Chem., Int. Ed. 2005, 44, 7601-7605.

(9) Nolte, P.; Stierle, A.; Kasper, N.; Jin-Phillipp, N. Y.; Reichert, H.; Rühm, A.; Okasinski, J.; Dosch, H.; Schöder, S. Combinatorial HighEnergy X-Ray Microbeam Study of the Size-Dependent Oxidation of Pd Nanoparticles on $\mathrm{MgO}(100)$. Phys. Rev. B 2008, 77, 115444.

(10) Harding, C. J.; Kunz, S.; Habibpour, V.; Heiz, U. Microkinetic Simulations of the Oxidation of CO on Pd Based Nanocatalysis: a Model Including co-dependent Support Interactions. Phys. Chem. Chem. Phys. 2008, 10, 5875-5881.

(11) Kunz, S.; Schweinberger, F. F.; Habibpour, V.; Röttgen, M.; Harding, C.; Arenz, M.; Heiz, U. Temperature Dependent CO Oxidation Mechanism on Size-Selected Clusters. J. Phys. Chem. C 2010, 114, 1651-1654.

(12) Kaden, W. E.; Wu, T.; Kunkel, W. A.; Anderson, S. L. Electronic Structure Controls Reactivity of Size-Selected Pd Clusters Adsorbed on $\mathrm{TiO}_{2}$ Surfaces. Science 2009, 326, 826-829.

(13) Yoon, B.; Landman, U.; Habibpour, V.; Harding, C.; Kunz, S.; Heiz, U.; Moseler, M.; Walter, M. Oxidation of Magnesia-Supported $\mathrm{Pd}_{30}$ Nanoclusters and Catalyzed CO Combustion: Size-Selected Experiments and First-Principles Theory. J. Phys. Chem. C 2012, 116, 9594-9607.

(14) Moseler, M.; Walter, M.; Yoon, B.; Landman, U.; Habibpour, V.; Harding, C.; Kunz, S.; Heiz, U. Oxidation State and Symmetry of Magnesia-Supported $\mathrm{Pd}_{13} \mathrm{O}_{x}$ Nanocatalysts Influence Activation Barriers of CO Oxidation. J. Am. Chem. Soc. 2012, 134, 7690-7699.

(15) Bernhardt, T. M.; Heiz, U.; Landman, U. Chemical and Catalytic Properties of Size-Selected Free and Deposited Clusters. In Nanocatalysis; Heiz, U., Landman, U., Eds.; Springer-Verlag: Berlin, 2007; pp 1-191.
(16) Penner, S.; Bera, P.; Pedersen, S.; Ngo, L. T.; Harris, J. J. W.; Campbell, C. T. Interaction of $\mathrm{O}_{2}$ with Pd Nanoparticles on a$\mathrm{Al}_{2} \mathrm{O}_{3}(0001)$ at Low and High $\mathrm{O}_{2}$ Pressures. J. Phys. Chem. B 2006, $110,24577-24584$.

(17) Meusel, I.; Hoffmann, J.; Hartmann, J.; Heemeier, M.; Bäumer, M.; Libuda, J.; Freund, H.-J. The Interaction of Oxygen with AluminaSupported Palladium Particles. Catal. Lett. 2001, 71, 5-13.

(18) Wu, T.; Kaden, W. E.; Kunkel, W. A.; Anderson, S. L. SizeDependent Oxidation of $\operatorname{Pd}_{\mathrm{n}}(n \leq 13)$ on Alumina/NiAl(110): Correlation with Pd Core Level Binding Energies. Surf. Sci. 2009, 603, 2764-2770.

(19) Robles, R; Khanna, S. N. Oxidation of $\mathrm{Pd}_{\mathrm{n}}(\mathrm{n}=1-7,10)$ Clusters Supported on Alumina/NiAl(110). Phys. Rev. B 2010, 82, 085428.

(20) Huber, B.; Koskinen, P.; Häkkinen, H.; Moseler, M. Oxidation of Magnesia-Supported Pd-Clusters Leads to the Ultimate Limit of Epitaxy with a Catalytic Function. Nat. Mater. 2006, 5, 44-47.

(21) von Gynz-Rekowski, F.; Ganteför, G.; Kim, Y. D. Interaction of Pd Cluster Anions $\left(\mathrm{Pd}_{\mathrm{n}}^{-}, n<11\right)$ with Oxygen. Eur. Phys. J. D 2007, $43,81-84$.

(22) Hintz, P. A.; Ervin, K. M. Chemisorption and Oxidation Reactions of Nickel Group Cluster Anions with $\mathrm{N}_{2}, \mathrm{O}_{2}, \mathrm{CO}_{2}$, and $\mathrm{N}_{2}$ O. J. Chem. Phys. 1995, 103, 7897-7906.

(23) Andersson, M.; Rosén, A. Adsorption and Reactions of $\mathrm{O}_{2}$ and $\mathrm{D}_{2}$ on Small Free Palladium Clusters in a Cluster-Molecule Scattering Experiment. J. Phys.: Condens. Matter 2010, 22, 334223.

(24) Ramond, T. M.; Davico, G. E.; Hellberg, F.; Svedberg, F.; Salén, P.; Söderqvist, P.; Lineberger, W. C. Photoelectron Spectroscopy of Nickel, Palladium, and Platinum Oxide Anions. J. Mol. Spectrosc. 2002, $216,1-14$.

(25) Huber, B.; Häkkinen, H.; Landman, U.; Moseler, M. Oxidation of Small Gas Phase Pd Clusters: A Density Functional Study. Comput. Mater. Sci. 2006, 35, 371-374.

(26) Kalita, B.; Deka, R. C. Reaction Intermediates of CO Oxidation on Gas Phase $\mathrm{Pd}_{4}$ Clusters: A Density Functional Study. J. Am. Chem. Soc. 2009, 131, 13252-13254.

(27) Lang, S. M.; Frank, A.; Fleischer, I.; Bernhardt, T. M. Is gold actor or spectator in the reaction of small $\mathrm{Au}_{\mathrm{n}} \mathrm{Pd}_{\mathrm{m}}{ }^{+}$clusters with $\mathrm{O}_{2}$ ? Eur. Phys. J. D 2013, 67:19, 1-7.

(28) Lang, S. M.; Fleischer, I.; Bernhardt, T. M.; Barnett, R. N.; Landman, U. $\mathrm{Pd}_{6} \mathrm{O}_{4}{ }^{+}$: An Oxidation Resistant Yet Highly Catalytically Active Nano-Oxide Cluster. J. Am. Chem. Soc. 2012, 134, 2065420659.

(29) Bernhardt, T. M. Gas-Phase Kinetics and Catalytic Reactions of Small Silver and Gold Clusters. Int. J. Mass Spectrom. 2005, 243, 1-29.

(30) Keller, R.; Nöhmeier, F.; Spädtke, P.; Schönenberg, M. H. CORDIS - An Improved High-Current Ion Source for Gases. Vacuum 1984, 34, 31-35.

(31) Lang, S. M.; Schnabel, T.; Bernhardt, T. M. Reactions of Carbon Monoxide with Free Palladium Oxide Clusters: Strongly Size Dependent Competition between Adsorption and Combustion. Phys. Chem. Chem. Phys. 2012, 14, 9364-9370.

(32) Lang, S. M.; Frank, A.; Bernhardt, T. M. Activation and Catalytic Dehydrogenation of Methane on Small $\mathrm{Pd}_{\mathrm{x}}^{+}$and $\mathrm{Pd}_{\mathrm{x}} \mathrm{O}^{+}$ Clusters. J. Phys. Chem. C 2013, 117, 9791-9800.

(33) Schuhmacher, E. DETMECH - Chemical Reaction Kinetics Software; University of Bern, Chemistry Department: Bern, 2003.

(34) Steinfeld, J. I.; Francisco, J. S.; Hase, W. L. Chemical Kinetics and Dynamics, 2nd ed; .Prentice Hall: Upper Saddle River, NJ, 1999.

(35) Bernhardt, T. M.; Hagen, J.; Lang, S. M.; Popolan, D. M.; Socaciu-Siebert, L. D.; Wöste, L. Binding Energies of $\mathrm{O}_{2}$ and $\mathrm{CO}$ to Small Gold, Silver, and Binary Silver-Gold Cluster Anions from Temperature Dependent Reaction Kinetics Measurements. J. Phys. Chem. A 2009, 113, 2724-2733.

(36) Lang, S. M.; Bernhardt, T. M.; Barnett, R. N.; Yoon, B.; Landman, U. Hydrogen-Promoted Oxygen Activation by Free Gold Cluster Cations. J. Am. Chem. Soc. 2009, 131, 8939-8951.

(37) Barnett, R. N.; Landman, U. Born-Oppenheimer MolecularDynamics Simulations of Finite Systems: Structure and Dynamics of $\left(\mathrm{H}_{2} \mathrm{O}\right)_{2}$. Phys. Rev. B 1993, 48, 2081-2097. 
(38) Troullier, N.; Martins, J. L. Efficient Pseudopotentials for PlaneWave Calculations. Phys. Rev. B 1991, 43, 1993-2006.

(39) Perdew, J. P.; Burke, K.; Ernzerhof, M. Generalized Gradient Approximation Made Simple. Phys. Rev. Lett. 1996, 77, 3865-3868.

(40) Shim, I.; Ginherich, K. A. Electronic Structure and Bonding in the $\mathrm{Pd}_{2}$ Molecule by All Electron Ab Initio HF-CI Calculations and Mass Spectrometric Measurements. J. Chem. Phys. 1984, 80, 51075119.

(41) American Institute of Physics (AIP) Handbook; Gray, E. G., Ed.; McGraw-HIll: New York, 1972.

(42) Efremenko, I.; Sheintuch, M. Quantum Chemical Study of Neutral and Single Charged Palladium Clusters. J. Mol. Catal. A: Chemical 2000, 160, 445-451.

(43) Kalita, B.; Deka, R. C. Stability of Small $\mathrm{Pd}_{\mathrm{n}}(\mathrm{n}=1-7)$ Clusters on the Basis of Structural and Electronic Properties: A Density Functional Approach. J. Chem. Phys. 2007, 127, 244306.

(44) Sanchez, A.; Abbet, S.; Heiz, U.; Schneider, W.-D.; Häkkinen, H.; Barnett, R. N.; Landman, U. When gold is not noble: Nano-scale gold catalysts. J. Phys. Chem. A 1999, 103, 9573-9578.

(45) Häkkinen, H.; Abbet, S.; Sanchez, A.; Heiz, U.; Landman, U. Structural, Electronic, and Impurity-Doping Effects in Nanoscale Chemistry: Supported Gold Nanoclusters. Angew. Chem., Int. Ed. 2003, 42, 1297-1300.

(46) Yoon, B.; Häkkinen, H.; Landman, U.; Wörz, A. S.; Antonietti, J.-M.; Abbet, S.; Judai, K.; Heiz, U. Charging Effects on Bonding and Catalyzed Oxidation of $\mathrm{CO}$ on $\mathrm{Au}_{8}$ Clusters on $\mathrm{MgO}$. Science 2005, 307, 403-407.

(47) Schalow, T.; Brandt, B.; Laurin, M.; Schauermann, S.; Guimond, S.; Kuhlenbeck, H.; Libuda, J.; Freund, H.-J. Formation of Interface and Surface Oxides on Supported Pd Nanoparticles. Surf. Sci. 2006, $600,2528-2542$. 